\title{
El uso de la fuerza contra el Estado Islámico en Irak y Siria: problemas de fundamentación jurídica*
}

\author{
The use of force against Islamic State in Syria and Iraq: \\ problems of legal basis
}

\section{Pilar Pozo SERRANo}

Profesora Titular de Derecho Internacional Público y Relaciones Internacionales

Universidad de Valencia

pilar.pozo@uv.es

\begin{abstract}
Resumen: La campaña militar en curso contra el Estado Islámico en Irak y Siria suscita problemas sobre el posible ejercicio del derecho de legítima defensa frente a ataques de actores no estatales en otros Estados. El contenido de las normas internacionales en este ámbito es controvertido y la práctica estatal resulta ambigua y poco concluyente. El artículo analiza las bases jurídicas invocadas por los Estados para justificar sus operaciones militares contra el Estado Islámico. El consentimiento proporcionado por el gobierno de Irak, no existe en el caso de Siria, dejando el derecho de legítima defensa como única base posible. El amplio respaldo de los Estados al uso de la fuerza contra el Estado Islámico va unido a posturas confrontadas en cuanto a la necesidad de consentimiento del Estado territorial al uso de la fuerza sobre su territorio.
\end{abstract}

Palabras clave: legítima defensa, actores no estatales, ataque armado, Estado Islámico, Irak.

\begin{abstract}
Current military campaign against the Islamic State in Iraq and Syria raises the question of the admissibility of the right to use force in self-defence against attacks by non-State actors in other States. International law in this area remains controversial and State practice ambiguous and inconsistent. This article analyses the legal basis invoked by States to justify their military operations against ISIL. Consent provided by the Iraqi government is lacking in the case of Syria, leaving only self-defence as feasible legal basis. The broad support for the use of force against Islamic State sides with conflicting views regarding the need of territorial State consent to the use of force on its territory.
\end{abstract}

Keywords: self-defence, non-State actors, armed attack, Islamic State, Iraq.

Sumario: I. INTRODUCCIÓN. II. ORIGEN Y EVOLUCIÓN DEL ESTADO ISLÁMICO: DE FILIAL DE AL QAEDA A «PROTO-ESTADO» TERRORISTA. 1. El carácter iraquí del grupo y su vinculación formal con Al Qaeda. 2. La implicación en el conflicto sirio y el auge del Estado Islámico. III. LA SOLICITUD DE ASISTENCIA MILITAR CONTRA EL ESTADO ISLÁMICO POR IRAK: INTERVENCIÓN MILITAR POR INVITACIÓN Y CONSENTIMIENTO DEL ESTADO TERRITORIAL. 1. La solicitud de asistencia militar por el gobierno iraquí y el condicionamiento de la respuesta aliada. 2. La intervención por invitación y el consentimiento del Estado: requisitos de validez. 3. Valoración de la solicitud de intervención militar del gobierno de Irak como base jurídica. IV. LA LEGITIMA DEFENSA COMO BASE JURÍDICA DE LAACCIÓN MILITAR CONTRA EL ESTADO ISLÁMICO. 1. Consideraciones previas: estado de la práctica internacional sobre legítima defensa frente a actores no estatales. 1.1. La calificación de los usos de la fuerza por actores no estatales, y no imputables a un Estado, como «ataque armado». 1.2. Los atentados del 11 de septiembre de 2001 y la reacción de la comunidad internacional. 2. Las posturas sobre el uso de la fuerza en legítima defensa contra objetivos del Estado Islámico en Siria. 2.1. Derecho de legítima defensa colectiva en apoyo de Irak, e individual de algunos miembros de la coalición internacional. 2. La posición de Siria y países aliados: consentimiento del Estado territorial y ejercicio del derecho de legítima defensa contra un actor no estatal. V. LA RESOLUCIÓN 2249 (2015) DEL CONSEJO DE SEGURIDAD: UNANIMIDAD SOBRE UN CONTENIDO MÍNIMO Y AMBIGÜEDAD EN CUANTO A SU SIGNIFICADO. 1. Efectos de las resoluciones del Consejo de Seguridad en el derecho de legítima defensa. 2. La resolución 2249 (2015) como eventual base jurídica para la acción contra Estado Islámico y otros grupos terroristas. VI. CONCLUSIONES.

* Este trabajo ha sido realizado en el marco del proyecto de investigación I+D+I Der 2015-64205-R (MINECO/FEDER) concedido por el Ministerio de Economía y Competitividad. 


\section{INTRODUCCIÓN}

E

n verano de 2014, el Estado Islámico controlaba extensas áreas en Siria e Irak, incluidos importantes núcleos urbanos. En respuesta a la solitud de ayuda de Irak se formó una coalición internacional, liderada por Estados Unidos, que empezó a actuar militarmente contra el Estado Islámico a finales de septiembre de 2014. El uso de la fuerza contra el Estado Islámico (EI) por la coalición ha renovado el debate sobre conceptos nucleares del régimen jurídico de la legítima defensa, entre ellos la posibilidad de calificar como ataque armado determinadas acciones de actores no estatales que no resultan imputables a un Estado ${ }^{1}$. De admitirse tal posibilidad, y la práctica internacional parece apuntar en ese sentido, surge la cuestión de la actitud del Estado en que se refugia el actor no estatal, cuyo territorio soportará el ejercicio del derecho de legítima defensa.

Los Estados participantes en la campaña militar contra el Estado Islámico así como Irak y Siria, en cuyo territorio se desarrollan las operaciones militares, han tenido que manifestar su posición jurídica sobre la calificación de los ataques del EI y las reacciones permitidas en Derecho internacional. Las declaraciones emitidas por Jefes de Estado o de Gobierno, u otros representantes estatales, y la correspondencia con el Consejo de Seguridad informando de las acciones militares emprendidas, o denunciando los ataques sufridos, pueden contribuir a orientar el desarrollo de las normas o de su interpretación en una determinada dirección. Discernir cuándo los comportamientos y declaraciones responden a consideraciones políticas y cuándo manifiestan una convicción jurídica resulta, sin embargo, complicado ${ }^{2}$. La fluidez del escenario en Siria e Irak, las reacciones estatales en respuesta a nuevos acontecimientos

1 También afecta a otras nociones esenciales en la legítima defensa, como necesidad y proporcionalidad, y aspectos específicamente relacionados con el concepto de «ataque armado», como su inminencia y gravedad.

2 Diferentes iniciativas han intentado aportar claridad en este ámbito mediante la formulación de principios que podrían considerarse asentados en la práctica, en unos casos, o que podrían servir como punto de partida de un debate posterior. En este sentido, Chatham House Principles of International Law on the Use of Force in Self-Defence, Leiden Policy Recomendations on Counter-Terrorism and International Law y los principios propuestos por D. BETHLEHEM en el American fournal of Internacional Law ( $\ll$ Self-Defence Against an Imminent or Actual Armed Attack by Nonstate Actors», AfIL, vol. 106, n. 4 [2012], pp. 769-767, posteriormente precisados en su respuesta a los comentarios recibidos, en «Principles of Self-Defence - A Brief Response», AfIL, vol. 107, n. 3 [2013], pp. 579-585). 
añaden una complejidad adicional. Aunque la práctica reciente presenta ambigüedades e inconsistencias que no invitan a extraer conclusiones definitivas sobre el alcance y significado de las normas implicadas ${ }^{3}$, en ocasiones parece reflejar la consolidación de ciertas tendencias. A veces está tan impregnada de consideraciones referidas a la excepcionalidad de las circunstancias que resulta difícil contemplar su generalización ${ }^{4}$.

Desde el principio, Estados Unidos y algunos países árabes condujeron ataques aéreos contra el EI, tanto en Irak como en Siria, invocando el derecho de legítima defensa colectiva en apoyo de Irak. Los demás países occidentales de la coalición limitaron sus operaciones al territorio iraquí. Este hecho, unido al énfasis de numerosos países en el consentimiento de Irak como base jurídica de sus acciones, podía ser interpretado como incertidumbre o rechazo de la posibilidad de operar lícitamente más allá del territorio de Irak ${ }^{5}$. Un año más tarde, tras los atentados de 13 de noviembre en París, reivindicados por el EI, y la adopción por el Consejo de Seguridad de la resolución 2249, otros países occidentales de la coalición empezaron a efectuar ataques aéreos también sobre territorio sirio. Dos fundamentos nuevos son invocados como base jurídica de las operaciones contra el EI, el derecho de legítima defensa individual de algunos miembros de la coalición y la resolución 2249 del Consejo de Seguridad, de 20 de noviembre de 2015.

El objetivo del presente trabajo es analizar las posturas adoptadas por los Estados en relación con los dos elementos ya apuntados del ejercicio del derecho de legítima defensa, que son centrales en el presente caso. En primer lugar, las condiciones para calificar ataques efectuados por actores no estatales como «ataque armado»y, en tales supuestos, los requisitos para ejercer la legítima defensa sobre el Estado en cuyo territorio se encuentra el grupo del que proceden. Con carácter previo se expone sintéticamente el contexto en

3 En este terreno, los análisis doctrinales adoptan un tono eminentemente tentativo, apuntando algún autor que los intentos de clarificar las normas sobre el derecho de legítima defensa contra actores no estatales son prematuros (HAKIMI, M., «Defensive Force Against Non-state actors: The State of Play», 91 International Law Studies, vol. 91 [2015], pp. 1-31, p. 3).

4 Flasch, O., «The Legality of the Air Strikes against ISIL in Syria: New Insights on the Extraterritorial Use of Force against Non-State Actors», Fournal on the Use of Force and International Law, vol. 3 (2016), n. 1, 37-69.

5 Arimatsu, L. y SchmitT, M. N., «Attacking 'Islamic State' and the Khorasan Group: Surveying the International Law Landscape», Columbia fournal of Transnational Law Bulletin, vol. 53, n. 1 (2014), p. 9; RUYS, T. y FERRERO, L., Divergent views on the content and relevance of the Ius ad Bellum in Europe and United States? The case of U.S-led military coalition against 'Islamic State', 10 de febrero, 2016, p. 6 (disponible en http://dx.doi.org/10.2139/ssrn.2731597). 
que se desarrolla el uso de la fuerza contra el Estado Islámico así como algunos aspectos de su evolución. Se procede después a analizar las bases invocadas por los Estados como fundamento jurídico de sus operaciones militares contra el Estado Islámico: el consentimiento o la invitación de Irak, en cuanto Estado víctima de los ataques, el ejercicio del derecho de legítima defensa individual y colectiva y, por último, la controvertida resolución 2249 (2015) del Consejo de Seguridad.

\section{ORIGEN Y EVOLUCIÓN DEL ESTADO ISLÁMICO:}

DE FILIAL DE AL QAEDA A «PROTO-ESTADO» TERRORISTA ${ }^{6}$

El actual Estado Islámico tiene sus orígenes en la organización yihadista creada por Zarqawi en 2003, con ocasión de la guerra de Irak, para luchar contra las fuerzas estadounidenses y contra el gobierno de mayoría chií que se establecería a continuación. La relación de Zarqawi con los líderes de Al Qaeda estuvo marcada por profundas divergencias que desembocarían finalmente en la ruptura. Tras la desvinculación de $\mathrm{Al}$ Qaeda, la rápida expansión territorial del Estado Islámico y la violencia empleada en el proceso singularizaron la percepción del grupo terrorista como una amenaza excepcional, situada en un plano diferente al de las restantes grupos ${ }^{7}$.

\section{El carácter iraquí del grupo y su vinculación formal con Al Qaeda}

En el año 2004, el grupo de Zarqawi quedó afiliado formalmente a Al Qaeda adoptando el nombre de Al Qaeda en Irak (AQI), pese a las diferencias que les separaban en cuanto a sus prioridades inmediatas. Ambos compartían la retórica común del terrorismo global contra los regímenes totalitarios y corruptos de los países musulmanes de Oriente Medio, así como contra Estados Unidos y demás países occidentales que les proporcionan respaldo militar y económico. Diferían respecto a los objetivos a corto plazo: Zarqawi pre-

6 A propósito de esta evolución del grupo como organización terrorista hacia la insurgencia y, por último, una aparente proto-estatalidad, vid. BARrETt, R., The Islamic State, The Soufan Group, Nueva York, noviembre 2014, p. 4.

7 Una amenaza «sin precedentes» para la paz y seguridad internacionales, en expresión de la resolución 2249, de 20 de noviembre de 2015, del Consejo se Seguridad. 
tendía promover la revolución violenta en los países de mayoría musulmana, mientras Al Qaeda postulaba primero el enfrentamiento con Estados Unidos y occidente. La vinculación de ambas organizaciones obedeció a razones de conveniencia: mientras Zarqawi ganaba en proyección, que redundaría probablemente en una mayor afluencia de recursos y combatientes, Al Qaeda establecía una filial en Irak, entonces principal escenario de la yihad, en un momento de particular debilidad.

Tras la muerte de Zarqawi, en 2006, el nuevo líder Abu Hamza, unificó AQI con otros grupos. La entidad resultante cambió su denominación a Estado Islámico de Irak (ISI, por sus siglas en inglés) conservando su condición de filial local de Al Qaeda. Cuando muere Abu Hamza en un ataque estadounidense, en el año 2010, el grupo ya se encontraba muy debilitado debido a la reforzada presión militar de Estados Unidos, que también había sabido aprovechar la oposición al ISI de algunos sectores suníes, apoyando y financiando las milicias denominadas «Consejos del Despertar».

La política sectaria del Primer Ministro Al Maliki, el control de las diferentes instituciones civiles y militares por miembros de su partido chií, agravó las tensiones entre las diferentes minorías. Se trataba de un gobierno enfrentado a los suníes, tanto seculares como islamistas, a los kurdos e incluso a los sectores chiíes de la oposición ${ }^{8}$. En particular, la exclusión de los suníes seculares generó un ambiente receptivo para la propaganda del Estado Islámico de Irak $^{9}$. La expansión del grupo se vería favorecida adicionalmente por la completa retirada de las tropas estadounidenses de Irak, en el año $2011^{10}$. Cuando estalló el conflicto en Siria, en 2011, la dirección del ISI se mantuvo inicialmente al margen prefiriendo concentrar sus acciones en Irak. La prolongación y el agravamiento del enfrentamiento de la población mayoritariamente suní con un gobierno dominado por la minoría alawita, secta chií, constituía sin embargo un escenario particularmente idóneo para establecer un nuevo frente

8 Khedery, A., «Iraq in Pieces. Breaking Up to Stay Together», Foreign Affairs, 22 de septiembre de 2015.

9 Sin fuerzas suficientes para seguir actuando como una insurgencia, el grupo pasó a efectuar atentados terroristas. A lo largo del año 2012, el ISI atacó varias prisiones para liberar y reagrupar a sus operativos con el fin de reconstituir el grupo, ahora bajo mando de Abu Bakr al Baghdadi. En verano de 2013 comenzaron sus ataques sistemáticos contra los miembros de las fuerzas de seguridad iraquíes así como el proceso de expansión territorial (BARRETT, R., The Islamic State..., cit., p. 12).

10 Byman, D. y WiLliams, J., «ISIS vs. Al Qaeda: Jihadism's global civil war», The National Interest, 24 febrero, 2015 , p. 4. 
de la yihad. Varios miembros sirios del ISI fueron enviados al norte de Siria, a mediados del 2011, bajo el mando de Al Golani. Este grupo recibió el apoyo de $\mathrm{Al}$ Zawahiri, que envió operativos de Al Qaeda para colaborar. Era el origen del Frente al Nusra, que iría creciendo con miembros procedentes tanto de Siria como del extranjero. La pasividad del régimen sirio, más interesado en combatir a la oposición moderada, facilitó la consolidación del grupo y su control de una extensión cada vez mayor del territorio sirio.

\section{La implicación en el conflicto sirio y el auge del Estado Islámico}

El conflicto de Siria había pasado a ser el principal foco de atracción de numerosos «combatientes» extranjeros. En abril de 2013, Abu Bakr alBaghdadi, el líder del ISI, intentó restablecer su autoridad sobre el grupo sirio y anunció la unificación con al-Nusra para formar el Estado Islámico de Irak y el Levante (EIIL) ${ }^{11}$ declarando que al-Nusra constituía una mera extensión del Estado Islámico de Irak. Esta decisión unilateral chocó con la oposición de los líderes de Al Nusra: Al Golani declaró la directa sumisión de su grupo a $\mathrm{Al}$ Qaeda y recurrió a Al Zawahiri para que resolviera la controversia. En mayo de 2013 Al Zawahiri se pronunció en contra de la unificación, señalando que Siria constituía el espacio propio del frente al Nusra y que Baghdadi debía limitarse a actuar en Irak, instando a ambos grupos a cooperar ${ }^{12}$. La proposición fue rechazada por Baghdadi que, en verano del 2013, emprendería acciones militares tanto en Irak como en Siria ${ }^{13}$. En este último país atacó de manera sistemática a otros grupos armados antigubernamentales, modificando de este modo el panorama de la insurgencia siria ${ }^{14}$.

Varios acontecimientos del año 2013 acabarían dando el impulso final al ascenso del Estado Islámico. En Irak, la dura represión de manifestacio-

11 Denominado frecuentemente ISIL, o ISIS, por sus siglas en inglés.

12 Al Jazeera, «Qaeda chief annuls Syrian-Iraqi jihad merger», 9 de junio de 2013, disponible en <www.aljazeera.com/news/middleeast/2013/06/2013699425657882.html>.

13 Finalmente, en febrero de 2014, el líder de Al Qaeda procedió a romper públicamente los vínculos del EIIL con la organización central (BARRETT, R., The Islamic State, cit., p. 12).

14 El grupo de Baghdadi detuvo a todos los activistas, civiles, líderes de otros grupos rebeldes que se le opusieron o cuestionaron su liderazgo, y combatió contra al Nusra en sus feudos principales, Raqqa y Aleppo. Los enfrentamientos entre el EIIL y otros grupos armados, de mayor o menor intensidad, son frecuentes. Sobre este particular, vid. ABOUZEID, R., Syria's uprising within an uprising, European Council on Foreign Relations 16 de enero, 2014, disponible en <www.ecfr. eu/article/commentary_syrias_uprising_within_an_uprising238>; BYMAN, D. y WILLIAMS, J., «ISIS vs. Al Qaeda...», cit. 
nes suníes por parte de los cuerpos de seguridad, y la violenta detención de un parlamentario suní que había manifestado su apoyo en el mes de diciembre, acentuó el sentido de discriminación y persecución de la población suní.

La captura de Faluya por las fuerzas del Estado Islámico de Irak y Levante, a principios de $2014^{15}$, marcó el inicio de una rápida campaña que culminaría en junio de ese mismo año, con la conquista de Mosul ${ }^{16}$, la segunda ciudad de Irak, y Tikrit, en la inmediata proximidad de rutas principales de comunicación ${ }^{17}$. Quedaban bajo control del EIIL importantes recursos económicos, infraestructura esencial y puestos estratégicos de la frontera con Siria. El 29 de junio de 2014 el grupo pasó a denominarse simplemente Estado Islámico, significando con ello la voluntad de establecer un califato en el territorio bajo su dominio ${ }^{18}$. Baghdadi se autoproclamó califa y líder de todos los musulmanes, estableciendo su capital en la ciudad siria de Raqqa ${ }^{19}$. En octubre, el Estado Islámico había tomado posiciones en las afueras de Bagdad e inició el asedio de la ciudad siria de Kobani, de población mayoritariamente kurda y próxima a la frontera con Turquía, ante la pasividad del Estado vecino.

15 Además de Faluya, otras ciudades importantes de la provincia de Anbar fueron quedando bajo control del EIIL como Haditha, Al Qaim, fronteriza con Siria, y Hit. Transcurrieron más de dos años antes de que Faluya pudiera ser recuperada por las fuerzas iraquíes con el apoyo de la coalición internacional, el 26 de junio de 2016 (página oficial del Ministerio de Asuntos Exteriores de Francia, <www.diplomatie.gouv.fr/en/country-files/iraq/events/article/iraq-retaking-of-thecity-of-falluja $>$ [26-06-16].

16 Ante la ofensiva yihadista buena parte de los miembros del Ejército iraquí huyó de la ciudad, abandonando abundante material militar, incluido armamento pesado y vehículos. El desmoronamiento del Ejército ponía de manifiesto la gravedad de la situación y la incapacidad del gobierno de Irak para hacer frente a la crisis en solitario. Las Fuerzas Armadas iraquíes también habían sufrido el sectarismo del Primer Ministro, que purgó a la oficialidad para eliminar a potenciales oponentes. La consiguiente disminución de mandos preparados, desmotivación y desorden pudieron contribuir a su colapso ante una insurgencia excelentemente entrenada (Laub, Z., Islamic State, Council on Foreign Relations Backgrounders, 10 agosto 2016).

17 European Parliamentary Research Service, Briefing, The international coalition to counter ISIL/ Da'esh, PE 551.330, 17 de marzo de 2015, p. 3.

18 El reconocimiento de su liderazgo en el mundo musulmán es marginal, algunos grupos yihadistas establecidos en diferentes países han declarado su apoyo y sumisión al Estado Islámico, otros se han limitado a manifestar su reconocimiento por los éxitos alcanzados en el campo de batalla, y entre sus enemigos declarados se encuentran los regímenes de la región y los grupos armados de la oposición siria (BARRETT, R., The Islamic State, p. 18).

19 European Parliamentary Research Service, Briefing, Understanding the rise of ISIL/Da'esh (the 'Islamic State'),PE 551.329, 17 de marzo de 2015. 
Para designar al grupo en su forma actual se utilizan diferentes términos. En los medios anglófonos, la denominación más habitual es ISIS (Islamic State in Irak and Syria) o ISIL (Islamic State in Irak and Levant). El equivalente en castellano es Estado Islámico de Irak y Levante (EIIL), utilizado en la versión oficial de los documentos de Naciones Unidas en español. También es conocido como Daesh, la transcripción del acrónimo árabe utilizado por sus detractores y que el grupo considera peyorativo. Este trabajo utiliza la denominación asumida por el grupo en cada etapa que es, en la actualidad, la de Estado Islámico (EI).

Como indica su denominación, el Estado Islámico aspira a crear una verdadera estructura estatal: retener el control del territorio que ocupa en Siria e Irak y ampliar su extensión; consolidar su poder económico y militar con el propósito, entre otros, de borrar lo que considera fronteras artificiales de Oriente Medio y estados árabes disfuncionales ${ }^{20}$. La existencia y actividad del EI representa un fuente de inestabilidad no sólo para los países cuyo territorio controla parcialmente, Siria e Irak, sino para toda la región especialmente para países vecinos como Turquía, Jordania, Líbano y Arabia Saudí ${ }^{21}$.

En otro plano, la determinación y audacia que han caracterizado las acciones militares del EI han servido de motivación para grupos yihadistas que operan en zonas en conflicto donde amplias porciones de territorio no están bajo control efectivo del gobierno central, por ejemplo Libia, Nigeria y la zona del Sahel ${ }^{22}$.

Por último, el EI ha demostrado su capacidad para inspirar también ataques terroristas de grandes proporciones, como los efectuados en Túnez, Turquía y en países europeos como Francia. Su ideología radical, la desmedida violencia que emplea, y esa posibilidad de alentar de manera más o menos directa atentados en países muy distantes, ha tenido el efecto de aglutinar en su contra a buen número de Estados y actores no estatales. Al mismo tiempo, la división entre chiís y sunís, las aspiraciones nacionalistas kurdas, las luchas de poder entre las potencias regionales, particularmente Arabia Saudí e Irán,

20 Ahram, A. I. y Lust, E., «The Decline and Fall of the Arab State», Survival, vol. 58, n. 2 (2016), pp. 7-34.

21 De manera gráfica se ha señalado que el Estado Islámico es percibido por la familia real Saudí como sólo una molestia, no como una amenaza vital. Pese a la campaña de atentados contra objetivos gubernamentales y chí́s, las dimensiones y recursos del Estado Islámico no son suficientes para generar la alarma. En este sentido, BunZEL, C., The Kingdom and the Caliphate. Duel of the Islamic States, Carnegie Endowment for International Peace, Washington, 2016.

22 European Parliamentary Research Service, The international coalition..., cit., p. 2. 
pero también Turquía ${ }^{23}$, así como sus alianzas con los grandes poderes, Estados Unidos ${ }^{24} \mathrm{y}$ Rusia, impiden una cooperación plena, y por tanto eficaz, entre los enemigos del Estado Islámico ${ }^{25}$.

\section{LA SOLICITUD DE ASISTENCIA MILITAR CONTRA EL ESTADO ISLÁMICO POR IRAK: INTERVENCIÓN MILITAR POR INVITACIÓN Y CONSENTIMIENTO DEL ESTADO TERRITORIAL}

La mayoría de Estados de la coalición internacional han justificado su intervención contra el Estado Islámico como respuesta a la expresa solicitud de ayuda formulada por las autoridades iraquíes. El significado y alcance del consentimiento, no obstante, deben ser matizados en función de las circunstancias concurrentes.

\section{La solicitud de asistencia militar por el gobierno iraquí y el condicionamiento de la respuesta aliada}

En la solicitud de ayuda de Irak, también en la respuesta de Estados Unidos y del resto de países, se pueden distinguir dos fases. En la primera, antes de la caída de Mosul en manos del EIIL el 8 de junio de 2014, Irak había solicitado

23 Reino Unido, House of Commons, Foreign Affairs Committee, The extension of offensive British military operations to Syria, Second Report of Session 2015-16, HC 457, 3 de noviembre de 2015, p. 7.

24 Estados Unidos y Rusia mantienen una posición radicalmente opuesta respecto al régimen de $\mathrm{Al}$ Assad. Este elemento no sólo lleva a la adopción de diferentes cursos de actuación contra el Estado Islámico sino, lo que es más importante, a sustentar estrategias para la resolución del conflicto sirio difíciles de conciliar en la práctica. Estados Unidos considera, y esto es relevante en la concepción de la legítima defensa frente a actores no estatales, que el presidente sirio «ha demostrado que no puede ni podrá reprimir esa amenaza, incluso al adoptar medidas que benefician el reclutamiento que llevan a cabo los extremistas» (Consejo de Seguridad, 7565ª sesión, 20 de noviembre de 2015, S/PV.7565, p. 4).

25 En este sentido, Fronson, J. y Simon, S., «ISIS: The Dubious Paradise of Apocalipse Now», Survival, vol. 57, n. 3 (2015), pp. 7-56. Los autores analizan la naturaleza del Estado Islámico, los factores que han alimentado la rápida expansión y los puntos débiles de la organización, para evaluar a continuación las estrategias de lucha contra el EIIL y sus perspectivas de éxito. Queda fuera de los límites de este trabajo la valoración jurídica de la ayuda militar de Estados a los grupos de la oposición siria, pero la cuestión surge de modo ineludible al analizar la licitud del uso de la fuerza en su territorio. El inicio de las operaciones militares de Rusia contra el Estado Islámico, a solicitud y en coordinación con el gobierno de sirio hacen resaltar más, si cabe, la ausencia de dicho consentimiento en la campaña de la coalición. 
la asistencia militar de algunos países, Estados Unidos especialmente, en el marco de convenios bilaterales ${ }^{26}$. El Primer Ministro Al Maliki había instado a Estados Unidos a efectuar bombardeos aéreos o ataques mediante drones contra objetivos del EIIL en su territorio. Al amparo del Acuerdo marco estratégico con Irak, Estados Unidos envió personal militar en funciones de inteligencia y entrenamiento de las fuerzas iraquíes y kurdas, excluyendo expresamente la participación en misiones de combate, y proporcionó igualmente equipamiento y munición ${ }^{27}$. La Administración estadounidense, sin embargo, se negó a emprender los ataques solicitados por el Primer Ministro argumentando que sólo un gobierno iraquí representativo estaría en condiciones de combatir eficazmente al EIIL y recibir el apoyo de otros aliados. El Primer Ministro iraquí había ignorado reiteradamente los requerimientos que le había dirigido Estados Unidos urgiéndole a formar un gobierno representativo conforme a las exigencias de la propia constitución iraquí. Al Maliki era visto como responsable de la crisis en buena medida, al haber alimentado con sus políticas sectarias la radicalización entre miembros de las minorías marginadas ${ }^{28}$.

La negativa a intervenir de Estados Unidos conoció excepciones. El 8 de agosto, la Casa Blanca anunció el desarrollo de una campaña de ataques aéreos de precisión con dos objetivos: por un lado, la protección del personal e instalaciones estadounidenses en Erbil, la capital de la región autónoma del Kurdistán iraquí ${ }^{29} \mathrm{y}$, por otro, el apoyo humanitario a la población yazidí refugiada en las montañas de Sinjar, poniendo fin a un asedio del $\mathrm{EI}^{30}$ que entrañaba

26 Las bases de la cooperación entre Estados Unidos e Irak se encuentran en dos tratados adoptados en la misma fecha, el 17 de noviembre de 2008, se trata del Strategic Framework Agreement for a Relationship of Friendship and Cooperation between the United States of America and the Republic of Iraq, que remite para aspectos específicos de defensa y del estatuto del personal militar al Agreement Between the United States of America and the Republic of Iraq On the Withdrawal of United States Forces from Iraq and the Organization of Their Activities during Their Temporary Presence in Iraq.

27 The White House, Office of the Press Secretary, Statement by the President on ISIL, 10 de septiembre, 2014 <www.whitehouse.gov/the-press-office/2014/09/10/statement-president-isil-1>.

28 Sobre este aspecto, véase el análisis de Fronson, J. y SimON, S., «ISIS: The Dubious Paradise...», cit., pp. 7-56.

29 The White House, Office of the Press Secretary, Background Briefing by Senior Administration Officials on Iraq, 8 de agosto de 2014, <www.whitehouse.gov/the-press-office/2014/08/08/background-briefing-senior-administration-officials-iraq $>$. En este caso, la nota informativa señala explícitamente que la autorización presidencial del uso de la fuerza está abierta a intervenciones posteriores en la medida en que se detecten amenazas para el personal o instalaciones estadounidense en cualquier parte del país.

30 Durante el mes de agosto, el Estado Islámico se había apoderado de Sinjar y poblaciones cercanas, cometiendo matanzas entre sus habitantes, mayoritariamente yazidíes. El éxodo de las 
elevado riesgo de genocidio ${ }^{31}$. Esta campaña limitada de ataques aéreos apoyando la acción de fuerzas kurdas e iraquíes sobre el terreno mejoró la crisis humanitaria específicamente contemplada y frenó el avance yihadista hacia el kurdistán. Fuera de esos supuestos, la prestación de cobertura aérea contra el EI siguió supeditada a la previa constitución de un gobierno representativo y también a la formación de una amplia coalición internacional ${ }^{32}$.

En la segunda fase, cuando la pérdida de Mosul agudizó la necesidad de recibir una ayuda militar adecuada, el gobierno iraquí llevó la situación al Consejo de Seguridad, mediante carta de 25 de junio de 2014, pidiendo a las Naciones Unidas y a la comunidad internacional que reconocieran «la amenaza excepcionalmente peligrosa a la que se enfrenta tanto nuestro país como la comunidad internacional en su conjunto» y solicitando ayuda en forma de «adiestramiento militar, tecnología avanzada y las armas necesarias para impedir que los terroristas creen bases de operaciones y zonas de seguridad». Una asistencia, subrayaba, que debía «ser compatible con los acuerdos bilaterales y multilaterales y respetar plenamente la soberanía nacional». La carta se había referido previamente a las atrocidades cometidas por el EIIL, a su avance territorial y enfatizaba el agravamiento de la situación debido a los ataques operados por la organización desde bases situadas en Siria ${ }^{33}$.

La formación de un nuevo gobierno en Irak con Al Abadi como Primer Ministro, el 11 de agosto de 2014, desbloqueó la situación. En septiembre, el Presidente Obama anunció su decisión de formar una coalición militar contra el Estado Islámico, con el objetivo de «debilitar y finalmente destruir el EI mediante una estrategia (...) integral e ininterrumpida $\gg^{34}$. El nuevo gobierno

minorías de la zona, principalmente yazidíes y cristianos iraquíes, así como el asedio al que fueron sometidas por el EI, creó una situación de emergencia humanitaria y las denuncias de posible genocidio por alguna organización humanitaria y por miembros de la Administración estadounidense. Una acusación también formulada por Irak ante el Consejo de Seguridad al comunicar la grave amenaza a la que se encuentra sometido y solicitar la asistencia de la comunidad internacional (Doc. S/2014/440, 25 de junio de 2014).

31 Background Briefing on Iraq, 8 de agosto de 2014, cit.

32 Una coalición en la que se consideraba de esencial importancia la participación de estados árabes (vid., Statement by the President on ISIL, cit.)

33 Doc. S/2014/440, 25 de junio de 2014, Annex to the letter dated 25 fune 2014 from the Minister for Foreign Affairs of Iraq addressed to the Secretary-General. En otro momento se pide que los Estados adopten medidas contra las actividades dirigidas a facilitar el reclutamiento para el grupo y contra sus redes de apoyo de financiero, mediático y de otra naturaleza.

34 Statement by the President on ISIL, cit. El discurso delinea los cuatro elementos de la estrategia de lucha contra el terrorismo del EIIL. En primer lugar, una campaña de ataques aéreos sistemáticos allí donde se encuentren los terroristas, dejando abierta la opción de efectuar ataques fuera de 
de Irak, el 20 de septiembre de 2014, recurría de nuevo al Consejo de Seguridad manifestando su consentimiento expreso para recibir asistencia militar en forma de «cobertura aérea en coordinación con las fuerzas armadas iraquíes y de conformidad con el derecho internacional» ${ }^{35}$. Subrayaba, además, que el hecho de que el Estado Islámico hubiera establecido «un cobijo fuera de las fronteras del Iraq» representaba una amenaza directa para Irak y le había llevado a solicitar a Estados Unidos que dirigiera las iniciativas internacionales destinadas a «atacar los lugares donde se encuentra el EIIL y sus bastiones militares, con nuestro expreso consentimiento» ${ }^{36}$. Mientras tanto, la coalición internacional había ido tomando forma mediante las iniciativas diplomáticas desarrolladas con ocasión de la cumbre de la OTAN en Gales, del 3 a 4 de septiembre y, sobre todo, en la Conferencia sobre la paz y la seguridad en Irak, celebrada el 15 de septiembre en París, con la asunción de compromisos concretos por los países participantes ${ }^{37}$. Satisfechos los dos requisitos a los que Estados Unidos había condicionado la reanudación de cobertura aérea, el presidente Obama anunció el inicio de una campaña de ataques aéreos contra objetivos del EI. La declaración presidencial, de 23 de septiembre de 2014, subraya que las operaciones contra el Estado Islámico de Estados Unidos

Irak. En segundo lugar, asistencia militar a las fuerzas que combaten contra el EI sobre el terreno. Lo que se traduce, señala a continuación, en un incremento de la ayuda militar a las fuerzas de la oposición en Siria, quedando excluida la posibilidad de contar con el régimen de Assad, del que afirma que nunca podrá recuperar su perdida legitimidad. En tercer lugar, el recurso a los mecanismos de lucha contra el terrorismo de que Estados Unidos dispone para prevenir ataques del EI, que comprenden instrumentos contra la financiación del grupo, mejora de la información, contrarrestar su ideología y frenar el flujo de terroristas desde y hacia Oriente Medio.

35 Naciones Unidas, Consejo de Seguridad, Annex to the letter dated 20 September 2014 from the Permanent Representative of Iraq to the United Nations addressed to the President of the Security Council, S/2014/691, 22 de septiembre de 2014, segundo párrafo).

36 Ibidem.

37 Ministère des Affaires étrangères et du Développement international, Conclusiones de la Conferencia Internacional sobre Paz y Seguridad en Irak (París, 15 de septiembre de 2014), <www.diplomatie.gouv.fr/es/fichas-de-paises/irak/eventos/article/conclusiones-de-la-conferencia>. La conferencia contó con la presencia de los siguientes países y organizaciones internacionales: Alemania, Arabia Saudí, Bahréin, Bélgica, Canadá, China, Dinamarca, Egipto, Emiratos Árabes Unidos, España, Estados Unidos de América, Francia, Irak, Italia, Japón, Jordania, Kuwait, Líbano, Omán, Países Bajos, Qatar, Noruega, República Checa, Reino Unido, Rusia, Turquía, Liga de Estados Árabes, Organización de las Naciones Unidas y la Unión Europea. Los participantes en la Conferencia, además de manifestar su satisfacción por la formación de un nuevo gobierno en Irak, declararon que el Estado Islámico representaba una amenaza para Irak y «para la comunidad internacional en su conjunto» y manifestaron su compromiso de proporcionar al nuevo gobierno iraquí toda la asistencia necesaria en su lucha contra el grupo, incluida «una ayuda militar apropiada» (Conclusiones, apartado 4). 
abarcarían tanto Irak como Siria y menciona a los cinco Estados árabes de la coalición (Arabia Saudí, Emiratos Árabes Unidos, Jordania, Bahréin y Qatar) dispuestos a actuar también sobre territorio sirio ${ }^{38}$.

La declaración emitida a tal efecto anunciaba igualmente el comienzo simultáneo de ataques contra el grupo Khorasan, integrado por «experimentados operativos de Al Qaeda en Siria», con el objeto de detener planes terroristas contra Estados Unidos y sus aliados ${ }^{39}$.

\section{La intervención por invitación y el consentimiento del Estado: requisitos de validez}

En principio, la intervención militar de un Estado en el territorio de otro Estado que así lo ha solicitado es lícita en Derecho internacional ${ }^{40}$. Se trata de un corolario del principio de la soberanía de los Estados que cuenta con el respaldado de una amplia práctica estatal, como ha tenido ocasión de subrayar la Corte Internacional de Justicia ${ }^{41}$. Los trabajos de codificación de

38 Estados Unidos comenzó proporcionando apoyo aéreo, entrenamiento y munición al Gobierno Regional del Kurdistán de Irak y al Gobierno de Irak y otros Estados también efectuaron ataques aéreos para detener el avance del Estado Islámico en territorio de Irak. El Departamento de Defensa de Estados Unidos adoptó para la operación el nombre de Inberent Resolve, fijándose por objetivo «eliminar el grupo terrorista ISIL y la amenaza que representan para Irak, para la región y para el conjunto de la comunidad internacional». (Información disponible en la página oficial de la operación, Combined Joint Task Force Operation Inherent Resolve, Fact Sheet, $<w w w . i n h e r e n t r e s o l v e . m i l / A b o u t>$ ). En el caso de España, el Congreso autorizó la participación española en la operación conforme a la solicitud del Consejo de Ministros de 10 de octubre de 2014. Sobre la contribución española, ver la información publicada en la página oficial del Estado Mayor de la Defensa, Ministerio de Defensa de España, Operación Inherent Resolve, <www. emad.mde.es/MOPS/042-Iraq-IR/>.

39 The White House, Office of the Press Secretary, Statement by the President on Airstrikes in Syria, 23 de septiembre de 2014, <www.whitehouse.gov/the-press-office/2014/09/23/statement-president-airstrikes-syria>.

40 Es una cuestión pacífica en la doctrina, aunque sin ignorar la posible concurrencia de circunstancias que afecten a su validez, vid. en este sentido DosWALD-BECK, L., «The Legal Validity of Military Interventention by Invitation of the Government», British Yearbook of International Law, vol. 56 (1) (1986), p. 189; GRAY, C., International Law and the Use of Force, Oxford, OUP, 2008, p. 80; DinsteIn, Y., War, Agression and Self-Defence, Cambridge, Cambridge, Univ. Press, 2011, p. 118; CORTEN, O., Le droit contre la guerre. L'interdiction du recours à la forcé en droit international contemporain, Paris, Pédone, 2008, p. 389.

41 La Corte abordó el tema por vez primera en Military and Paramilitary Activities in and against Nicaragua (Nicaragua v. United States of America). Merits, Judgment. I.C.7. Reports 1986, p. 14, y reiteró sus conclusiones en Armed Activities on the Territory of the Congo (Democratic Republic of the Congo v. Uganda), Judgment, I.C.F. Reports 2005, p. 168. El razonamiento de la CIJ en este último asunto parte implícitamente de la premisa de que, en caso de demostrarse la concurrencia 
la Comisión de Derecho Internacional concurren en este mismo sentido, al recoger el consentimiento «válido de un Estado a la comisión por otro Estado de un hecho determinado» como circunstancia que excluye la ilicitud de un comportamiento que, en sí mismo, es contrario al Derecho internacional ${ }^{42}$. La definición de agresión propuesta por la Asamblea General también parte, implícitamente, de la licitud de la intervención militar consentida cuando enuncia entre los supuestos de agresión «la utilización de fuerzas armadas de un Estado que se encuentran en territorio de otro Estado con el acuerdo del Estado receptor, en violación de las condiciones establecidas en el acuerdo o la prolongación de su presencia en dicho territorio después de terminado el acuerdo» ${ }^{43}$.

Ahora bien, la intervención consentida debe respetar una serie de condiciones para ser lícita. La práctica internacional, relativamente clara y uniforme respecto a algunas, no resulta concluyente en otras suscitando interpretaciones divergentes. La interpretación de los requisitos relacionados con la noción de consentimiento estatal parece ser objeto de un amplio consenso doctrinal. En el comentario al artículo 20 del Proyecto de artículos sobre responsabilidad internacional, la Comisión de Derecho Internacional (CDI) ha señalado que, para determinar la validez del consentimiento, deben examinarse aspectos como la identificación del órgano que puede manifestar el consentimiento a una intervención militar, o la eventual relevancia de la «legitimidad

del consentimiento de la República Democrática del Congo (RDC) a la intervención militar de Uganda en su territorio, tal intervención sería lícita. En una cumbre celebrada el 8 de agosto de 1998, la RDC había acusado públicamente a Uganda de estar invadiendo su territorio. La Corte estimó que, si había existido un consentimiento anterior de la RDC, debía considerarse retirado a partir de la fecha en que formuló la denuncia (I.C.7. Reports 2005, p. 199, par. 53). Uganda intentó justificar su presencia y actividades militares posteriores a esa fecha, invocando de nuevo el consentimiento de la RDC durante un periodo de tiempo, recogido en varios Acuerdos. La Corte estimó que los tratados invocados regulaban aspectos del armisticio alcanzado, proceso de retirada de las tropas extranjeras y normalización de relaciones, pero no constituían consentimiento por parte de la RDC a la intervención ugandesa, con la excepción de la presencia militar en una región fronteriza contemplada en el acuerdo de Luanda (I.C.7. Reports 2005, p. 211, par. 105).

42 Proyecto de artículos sobre la responsabilidad internacional del Estado por hechos internacionalmente ilícitos, art. 20. Ver Informe de la Comisión de Derecho Internacional, Asamblea General, 56 periodo de sesiones, Suplemento $\mathrm{n}^{\circ} 10$ (A/56/10), 2001. El comentario al artículo 20 menciona en varias ocasiones diferentes modalidades de intervención militar (establecimiento de una base militar, establecimiento de tropas extranjeras) como ejemplos de comportamientos cuya ilicitud queda excluida por el consentimiento del Estado territorial.

43 Asamblea General, Resolución 3314 (XXIX), Definición de la agresión, 14 de diciembre de 1974, Anexo, artículo 3. e). 
del gobierno ${ }^{44}$. La CDI no aportaba respuestas a esas cuestiones, que no constituían materia del Proyecto de artículos, pero sí fijó condiciones que debían concurrir necesariamente para la validez de consentimiento: ser otorgado libremente, de manera clara y efectiva, y no estar viciado por error, fraude, corrupción o coacción ${ }^{45}$. Cuando el consentimiento del Estado que solicita la intervención militar reúne esas características, la intervención será valida mientras permanezca dentro de los límites del consentimiento manifestado. Así lo recoge el Instituto de Derecho Internacional en su resolución sobre «Asistencia militar solicitada ${ }^{46}$.

Por lo que se refiere a la autoridad de la que procede la solicitud de asistencia, existe igualmente un amplio consenso doctrinal en cuanto a la exigencia de que el consentimiento sea emitido por el gobierno formal del Estado, y de que se trate de un gobierno efectivo ${ }^{47}$. La valoración puede resultar problemática cuando, como sucede en el presente caso, el gobierno formal ha perdido el control efectivo sobre parte del territorio estatal. La postura que parece prevalecer en la práctica es que un gobierno sigue representando al Estado mientras no haya sido desplazado totalmente del poder y conserve, al menos, un control parcial. En este sentido, la relevancia otorgada en la práctica reciente a la legitimidad y la representatividad del gobierno frente a criterios puramente formales favorables a las autoridades establecidas ${ }^{48}$ no lle-

44 La negativa de Estados Unidos a prestar una modalidad de asistencia específicamente solicitada por el Primer Ministro Al Maliki (los ataques aéreos contra el EI) mientras no procediera a la formación de un gobierno inclusivo, no equivale a un rechazo pleno de su legitimidad. El gobierno estadounidense se mostró severamente crítico con sus políticas discriminatorias y condicionó su implicación en operaciones aéreas a la formación de un nuevo ejecutivo, pero mientras tanto colaboró con el gobierno de Irak en la lucha contra el EIIL proporcionando ayuda militar de otro tipo.

45 Ibidem.

46 Instituto de Derecho Internacional (IDI), Problèmes actuels du recours à la force en droit international. Sous-groupe C: Assistance militaire sollicitée, Sesión de Rodas, 2011, artículos 4 y 6. El contenido de la intervención cubierta por la invitación puede ser muy variado, el artículo 2 de la Resolución circunscribe su alcance a «situations of internal disturbances and tensions, such as riots, isolated and sporadic acts of violence and other acts of a similar nature, including acts of terrorism, below the threshold of non-international armed conflict in the sense of Article 1 of Protocol II Additional to the Geneva Conventions relating to the Protection of Victims of Non-International Armed Conflicts of 1977». A continuación señala que el objetivo de la asistencia militar es «to assist the requesting State in its struggle against non-State actors or individual persons within its territory, with full respect for human rights and fundamental freedoms.»

47 Brownlie, I., International Law and the Use of Force by States, Oxford, Clarendon Press, 1963, pp. 317-27; CORTEN, O., Le droit contre la guerre..., cit., pp. 403-415.

48 Weller, M., «Striking ISIL: Aspects of the Law on the Use of Force», ASIL Insights, vol. 19, n. 5 (2015). 
ga hasta el punto de aceptar la invitación a intervenir de un gobierno legítimo pero totalmente desprovisto de toda efectividad ${ }^{49}$, salvo previa autorización del Consejo de Seguridad ${ }^{50}$.

La asistencia militar a los grupos rebeldes, por el contrario, constituiría una violación del principio de no intervención. En este sentido se ha pronunciado expresamente la Corte Internacional de Justicia ${ }^{51}$, reconociendo la admisibilidad de la intervención a petición del gobierno de un Estado y rechazándola a petición de la oposición:

«it is difficult to see what would remain of the principie of non-intervention in international law if intervention, which is already allowable at the request of the government of a State, were also to be allowed at the request of the opposition.» ${ }^{52}$

Cuando la solicitud de asistencia militar es formulada por un gobierno en el marco de una guerra civil para hacer frente a las fuerzas rebeldes, la doctrina se divide. Para un amplio sector doctrinal, en caso de guerra civil, la asistencia militar de terceros Estados al gobierno violaría el principio de no intervención y el derecho de autodeterminación de los pueblos ${ }^{53}$. Es la postura asumida por el Instituto de Derecho Internacional en su resolución sobre «El principio de no intervención en guerras civiles», en la que se enuncia la prohibición de prestar asistencia militar a cualquiera de las partes en una guerra civil $^{54}$. Para otro sector, semejante prohibición carece de respaldo tanto en el Derecho internacional clásico ${ }^{55}$ como en la práctica más reciente. A juicio de

49 GraY, C., International Law..., cit., p. 92.

50 CORTEN, O., Le droit contre la guerre..., cit., pp. 441-442.

51 En el asunto de las actividades militares y paramilitares en y contra Nicaragua, la Corte determinó que el principio de no intervención prohibía «intervenir, directa o indirectamente, con o sin uso de la fuerza armada, en apoyo de la oposición interna en otro Estado» (I.C.F. Reports 1986, p. 108, para. 206).

52 I.C.F. Reports 1986, p. 126, para. 246.

53 Es la interpretación que CORTEN extrae tras un detallado análisis de práctica estatal (Le droit contre la guerre..., cit., pp. 448-482).

54 IDI, Resolution on the Principle of Non-Intervention in Civil Wars, sesión de Wiesbaden, 1975, artículo 2. A los efectos de la resolución, la noción de guerra civil comprende los conflictos armados no internacionales y aquellos conflictos que surjan dentro del territorio de un Estado en los que se enfrenten el gobierno establecido con uno o varios movimientos insurreccionales o, en ausencia de un gobierno formal, varios grupos se disputen el poder del Estado habiendo alcanzado la lucha armada cierta entidad por su intensidad y extensión (art. 1).

55 Su contenido había quedado recogido en gran medida por la resolución adoptada por el Instituto de Derecho Internacional el 8 de septiembre de 1900, en la sesión de Neuchâtel, titulada 
estos autores, la asistencia militar externa al gobierno sólo quedaría prohibida en caso de reconocimiento del estatuto de beligerancia al grupo o grupos insurgentes pues «la beligerancia reconocida por terceros países produce todos los efectos ordinarios de la neutralidad $\gg^{56}$. Cuando no hay reconocimiento de beligerancia, sería lícito intervenir militarmente en una guerra civil a petición del gobierno central pero no de los rebeldes, como ya se ha señalado ${ }^{57}$.

En la práctica, puede resultar conflictiva la misma determinación de que una situación constituye un supuesto de disturbios internos, en los que resultaría lícita la intervención militar a solicitud del gobierno pero no de la oposición, o una guerra civil, donde, como se ha señalado, la práctica estatal no ofrece un significado claro y la doctrina permanece dividida.

\section{Valoración de la solicitud de intervención militar del gobierno de Irak}

A la luz de las consideraciones apuntadas, ninguno de los aspectos problemáticos suscitados, como la pérdida de control efectivo sobre parte del territorio por parte del gobierno, su cuestionada legitimidad, o la posible prohibición de asistencia militar externa a las partes en una guerra civil, parece comprometer la validez del consentimiento del gobierno iraquí ni la licitud de la intervención. Las conclusiones de la doctrina en este sentido son prácticamente unánimes ${ }^{58}$.

Droits et devoirs des Puissances étrangères, au cas de mouvement insurrectionnel, envers les gouvernements établis et reconnus qui sont aux prises avec l'insurrection.

$56 \mathrm{Ibid}$., art. 7. El texto pone de manifiesto el carácter voluntarista del reconocimiento de beligerancia. Aunque los terceros Estados sólo pueden reconocer el estatuto de beligerancia si se cumplen una serie de requisitos, no están obligados a otorgar tal reconocimiento aunque tales requisitos se cumplan (art. 8).

57 Entre otros, Dinstein, Y., War, Agression..., cit., p. 119. La «beligerancia» es una noción jurídica compleja, se ha resaltado lo inusual de su reconocimiento y la incertidumbre en cuanto a algunos de sus elementos. Como ha señalado FERNÁNDEZ LIESA, la intrincada situación de la guerra civil española contribuyó a poner de manifiesto algunos de estos problemas contribuyendo al retroceso de la noción («La guerra civil española y del derecho internacional», La complejidad de la figura y la incertidumbre en cuanto a sus repercusiones REDI, n. 1, vol. LXI [2009], pp. 76-78) hasta caer en desuso (LoOTSTEEN, Y. M., «The Concept of Belligerency in International Law», Military Law Review, vol. 166 [2000], pp. 109-141).

58 En este sentido, Arimatsu, L. y Schmitt, M. N., «Attacking 'Islamic State'...», cit., p. 6; Byrne, M., «Consent and the use of force: an examination of 'intervention by invitation' as a basis for US drone strikes in Pakistan, Somalia and Yemen», Fournal on the Use of Force and International Law, vol. 3, n. 1 (2016), pp. 97-125, p. 102; DE HoOG, A., «Restrictivist Reasoning on the Ratione Personae Dimension of Armed Attacks in the Post 9/11 World», Leiden Fournal of International Law, vol. 29 (2016), pp. 19-42, p. 42; RuYs, T. y FERrero, L., Divergent views..., cit.; FlasCH, O., «The Legality of the Air Strikes...», cit., p. 38; Egan, B., «International Law, Legal Diplomacy, 
Desde la perspectiva de quienes consideran ilícita la intervención militar a invitación del gobierno en casos de guerra civil, el conflicto entre el gobierno iraquí y el Estado Islámico no entraría en tal categoría. La naturaleza del Estado Islámico no responde propiamente a la de un movimiento insurreccional iraquí, que pretenda desplazar al gobierno en el poder ${ }^{59}$. Se trata, de un grupo terrorista incluido como tal en listas elaboradas por Estados y organizaciones internacionales. $\mathrm{Al}$ mismo tiempo no es un fenómeno meramente interno: desarrolla actividades fuera de las fronteras iraquíes, cuenta con bases de operaciones en territorio sirio, donde se refugia y desde donde efectúa ataques contra Irak y sus objetivos trascienden el conflicto en Irak ${ }^{60}$.

En cualquier caso, si la invitación formal del gobierno iraquí puede considerarse base jurídica para justificar la licitud de los ataques realizados por la coalición en territorio iraquí, no cabe aplicar el mismo argumento a las operaciones militares en territorio sirio. Los argumentos jurídicos para justificar la licitud de las operaciones militares sobre Siria son más complejos y controvertidos.

\section{LA LEGÍTIMA DEFENSA COMO BASE JURÍDICA DE LA ACCIÓN MILITAR CONTRA EL ESTADO ISLÁMICO}

Aunque el gobierno iraquí haya dejado constancia de su «expreso consentimiento» a los ataques de la coalición internacional contra «los lugares donde se encuentra el EIIL» situados «fuera de las fronteras iraquíes», la intervención por invitación no puede legitimar la acción militar fuera del territorio del

and the Counter-ISIL Campaign: Some Observations», International Law Studies, vol. 92 (2016), pp. 235-248, p. 238; MARTIN, J. C., «Les frappes de la France contre l'EIIL en Syrie, à la lumière de la résolution 2249 (2015) du Conseil de sécurité», Questions of International Law (2016), pp. 3-14.

59 Más controvertida resulta la licitud del la asistencia militar estadounidense a algunos grupos de la oposición siria. Estados Unidos descartó toda colaboración con el Presidente Assad, «un régimen que aterroriza a su propia población y que nunca recuperará la legitimidad que ha perdido», optando en su lugar por «reforzar a la oposición como mejor contrapeso» al Estado Islámico (Statement by the President on ISIL, cit). En este sentido, vid. SсHмITT, M. N., «Legitimacy versus Legality Redux: Arming the Syrian Rebels», Fournal of National and Security Law \& Policy, vol. 7, pp. 139-159). A propósito de la noción de «legitimidad», el autor hace un llamamiento a la cautela antes de usarla como justificación de comportamientos contrarios al derecho internacional. En este caso, advierte «the United States needs to be comfortable with the prospect of contributing to the crystallization of a customary norm allowing other states to arm rebel groups in similar circumstances before it proceedes» (p. 159).

60 En este sentido RuYs, T. y Ferro, L., Divergent views..., cit., p. 6; Arimatsu, L. y Schmitt, M. N., «Attacking 'Islamic State'..., cit., p. 7. 
Estado cuyo gobierno solicita la intervención. El uso de la fuerza en respuesta a la solicitud del Estado víctima de un ataque armado que procede del exterior introduce en el ámbito de la legítima defensa colectiva, contemplada en el art. 51 de la Carta de las Naciones Unidas.

La iniciativa de formar una coalición para combatir contra el Estado Islámico contó con un amplio respaldo y el compromiso de asistencia de numerosos países. Sin embargo, el único país occidental que efectuó ataques aéreos sobre territorio sirio desde el principio de la campaña fue Estados Unidos. Los demás Estados europeos y Canadá confinaron sus intervenciones militares a los objetivos del EIIL en suelo iraquí, aunque no cuestionaron la licitud de las operaciones militares estadounidenses en Siria ${ }^{61}$.

Esta opción puede deberse a razones de distinta índole, políticas, económicas u operativas. Lo relevante a efectos del presente trabajo es determinar si responde a consideraciones de naturaleza jurídica: si los Estados actuaron sólo sobre territorio iraquí por falta de convicción en cuanto a la solidez de las bases jurídicas para intervenir lícitamente en Siria.

Estados Unidos cuenta con una larga práctica que muestra un claro posicionamiento favorable al ejercicio del derecho de legítima defensa individual y colectiva frente a actores no estatales.

Por el contrario, antes de participar en la coalición contra el Estado Islámico, pocos Estados europeos habían contemplado expresamente tal posibilidad, y siempre en términos muy prudentes ${ }^{62}$. La amplia participación en la campaña contra el EI ha modificado esta situación tras un breve proceso de evolución no exenta de ambigüedades y contradicciones.

61 Vid., RuYs, T. y Ferro, L., Divergent views..., cit., pp. 12-13; AKANDE, D., «The Airstrikes against Islamic State in Iraq and the Alleged Prohibition on Military Assistance to Governments in Civil Wars», EfIL Analysis, 2 febrero 2015, <www.ejiltalk.org/the-airstrikes-against-islamic-state-iniraq-and-the-alleged-prohibition-on-military-assistance-to-governments-in-civil-wars/> .

62 La Doctrina de Defensa de Holanda, publicada por el Ministerio de Defensa holandés en 2005, establece en el apartado relativo al derecho de legítima defensa: «An armed attack primarily involves operations by regular forces in the territory of another nation. Other cases, such as terrorist actions, can also be regarded as such under certain circumstances» (Netherlands Defence Doctrine, Ministry of Defence, The Hague, p. 33). El Libro Blanco del gobierno francés sobre la seguridad interior frente al terrorismo, adopta un enfoque similar (Secrétariat Général de la Défense Nationale, La France face au terrorisme: Livre Blanc du Gouvernement sur la sécurité intérieure face au terrorisme, Parías, 2006, p. 95). La práctica estatal no ofrece demasiados ejemplos, para un análisis de documentos e informes elaborados en el seno de diferentes organizaciones internacionales, vid. RUYS, T., «Armed Attack» and Article 51 of the Charter: Evolutions in Customary Law and Practice, Cambridge, Cambridge University Press, 2010, pp. 445-446. 


\section{Consideraciones previas: estado de la práctica internacional sobre legítima defensa frente a actores no estatales}

La reivindicación del derecho de legítima defensa para fundamentar los ataques contra el EI en Siria, reproduce dos de los elementos que fueron objeto de controversia en relación con los atentados terroristas del 11 de septiembre de 2001. En primer lugar, si el ataque ejecutado por un actor no estatal puede ser calificado como «ataque armado» a efectos del ejercicio de la legítima defensa. En segundo lugar, y en la medida en que para ejecutar un ataque desde el exterior contra un Estado los actores no estatales deben haberse refugiado o establecido bases de operaciones en el territorio de otro Estado, si el derecho de legítima defensa se puede ejercer sobre el territorio de ese Estado y en qué condiciones.

\subsection{La calificación de los usos de la fuerza por actores no estatales, y no imputables a un Estado, como «ataque armado»}

Antes de los atentados del 2001, la posibilidad de calificar el comportamiento de actores no estatales como un «ataque armado» a efectos de la aplicación del artículo 51, sólo había sido admitida de manera aislada en la doctrina ${ }^{63}$. La procedencia estatal del ataque armado parecía considerarse en práctica y doctrina mayoritarias una condición implícita, en la medida en que la legítima defensa es una excepción al principio de la prohibición del uso de la fuerza por los Estados en sus relaciones internacionales consagrado en el art. 2.4 de la Carta. En cualquier caso, esa fue la interpretación ofrecida por la Corte Internacional de Justicia en el asunto de las actividades militares y paramilitares en Nicaragua:

«it may be considered to be agreed that an armed attack must be understood as including not merely action by regular armed forces across an international border, but also «the sending by or on behalf of a State of armed bands, groups, irregulars or mercenaries, which carry out acts of armed

63 Dinstein y Tomuschat, por ejemplo, habían defendido esta postura (vid. DinsteIn, Y., War, Agression and Self-Defence, Cambridge, Cambridge University Press, 3d ed. 2001 pp. 213-215; Tomuschat, C., «International Law: Ensuring the Survival of Mankind on the Eve of a New Century. General Course of Public International Law», Recueil des Cours de l'Academy de Droit International, vol. 281 (1999), pp. 9-438, pp. 215-216). 
force against another State of such gravity as to amount to» (inter alia) an actual armed attack conducted by regular forces, «or its substantial involvement therein.» ${ }^{64}$

Varios aspectos del pronunciamiento merecen ser destacados. La Corte exige que exista cierta conexión entre el actor no estatal y un Estado para que el uso de la fuerza por el primero pueda ser calificado como «ataque armado» a los efectos del artículo 51 de la Carta. Recurriendo a la definición de agresión de la resolución 3314, la Corte contempla dos modalidades de conexión: el «envío por el Estado o en su nombre» del grupo armado, o la «sustancial participación» del Estado en los usos de la fuerza armada del actor no estatal contra otro Estado $^{65}$. En el primer supuesto, los ataques realizados por el actor no estatal serían imputables al Estado; en el segundo, no necesariamente. La sentencia no determina en qué consiste la «sustancial participación» pero sí excluye del concepto comportamientos como «la asistencia a los rebeldes en forma de provisión de armas o apoyo logístico o de otra naturaleza» ${ }^{66}$. Para un amplio sector doctrinal, la sentencia expresaba la interpretación del derecho consuetudinario reflejada en la práctica internacional hasta ese momento y del pronunciamiento de la Corte se derivaba que la conducta del Estado que proporciona refugio territorial al grupo armado no alcanzaría el umbral necesario para calificar el uso de la fuerza por ese grupo no estatal como un ataque armado a los efectos del artículo $51^{67}$. Esta restrictiva interpretación de la Corte sobre el alcance de la noción «sustancial participación» también suscitó críticas de algunos de los jueces ${ }^{68}$ y de parte de la doctrina, considerando que le había otorgado un significado más restringido ${ }^{69}$, pero que debía ser aplicado desde entonces ${ }^{70}$.

64 I.C.7. Reports 1986, p. 103, par. 195.

65 Resolución 3314 (XXIX), Definición de la agresión, 14 de diciembre de 1974, art. 3 g).

66 I.C.7. Reports 1986, p. 104, par. 195. En esos otros supuestos, la Corte señala que el Estado involucrado actuaría en contra del principio de no intervención.

67 Gray, C., The Use of Force..., pp. 175-7.

$68 \mathrm{Vid}$, las opiniones disidentes de los jueces Schwebel (I.C.7. Reports 1986, pp. 259-527, en par. 171) y Jennings (ibid., pp. 528-46, en pp. 543-4).

69 BeRMejo GarCíA, R., El marco jurídico internacional del uso de la fuerza: ambigüedades y límites, Pamplona, Civitas, 1993, pp. 287-9; Dinstein, Y., War, Agression..., cit., pp. 209, 221.

70 Resulta ilustrativa la opinión separada de la juez Higgins en la opinión consultiva de 2004: «There is, with respect, nothing in the text of Article 51 that thus stipulates that self-defence is available only when an armed attack is made by a State. That qualification is rather a result of the Court so determining in Military and Paramilitary Activities in and against Nicaragua... While accepting, as I must, that this is to be regarded as a statement of the law as it now stands» (Legal Consequences of the Construction of a Wall in the Occupied Palestinian Territory, Advisory Opinion, I.C.F. Reports 2004, pp. 207-18, par. 33, las cursivas son del original). 
Conviene destacar que la sentencia, incluso en esa postura restrictiva, ampara la equiparación de ciertos usos de la fuerza por actores no estatales que no son imputables a un Estado a un ataque armado a efectos del ejercicio del derecho de legítima defensa siempre que exista un grado suficiente de implicación estatal en los mismos. Del razonamiento de la Corte, pero también de las explicaciones proporcionadas por los jueces disidentes, se desprende que una tolerancia pasiva de la presencia de un grupo en el propio territorio no constituiría esa «participación sustancial».

La práctica estatal posterior parece desviarse de los parámetros señalados por la Corte Internacional de Justicia en el asunto Nicaragua. No existen la uniformidad ni la coherencia necesarias para afirmar la cristalización de una nueva interpretación de la noción de legítima defensa, pero sí parece haberse extendido una postura más flexible en cuanto a la admisibilidad de la legítima defensa frente a usos de la fuerza por actores no estatales que no son atribuibles a un Estado ${ }^{71}$. La práctica estatal opera una distinción entre el ejercicio de la legítima defensa contra un actor no estatal en el territorio de otro Estado y el uso de la fuerza contra el Estado mismo desde el que opera el actor no estatal $^{72}$. En el primer supuesto, al informar al Consejo de Seguridad de las acciones adoptadas en virtud del artículo 51, los Estados ponían de relieve que sus acciones habían sido dirigidas contra las instalaciones y los miembros del grupo $\operatorname{armado}^{73}$. Se abría paso en la práctica la reivindicación de un derecho a

71 En este sentido, RuYs, T., «Armed Attack»..., cit., p. 494, que acompaña a su conclusión el análisis de un amplio elenco de supuestos de la práctica internacional (pp. 368-485)

72 En este segundo caso, los Estados trataban de demostrar una implicación del Estado territorial en los ataques llevados a cabo por el grupo armado suficiente para soportar el ejercicio de la legítima defensa. En este sentido, el comunicado dirigido por Estados Unidos al Consejo de Seguridad, sobre el ataque llevado a cabo en Trípoli, en respuesta «a los actos contra ciudadanos e instalaciones estadounidenses» dirigidos por Libia durante un prolongado periodo, en particular el atentado efectuado en Berlín occidental, en octubre de 1986 (Consejo de Seguridad, Carta de fecha 14 de abril de 1986 dirigida al Presidente del Consejo de Seguridad por el Representante Permanente interino de los Estados Unidos de América ante las Naciones Unidas, S/17990, 14 de abril de 1986).

73 A título de ejemplo, puede verse la justificación proporcionada por Estados Unidos de los ataques aéreos realizados contra una instalación usada para producir armas químicas en Sudán y campos de entrenamiento en Afganistán, en respuesta a los atentados cometidos por la organización de Bin Laden contra las embajadas estadounidenses en Nairobi y Dar es Salaam, en 1998 (Consejo de Seguridad, Carta de fecha 20 de agosto de 1998 dirigida al Presidente del Consejo de Seguridad por el Representante Permanente de los Estados Unidos de América ante las Naciones Unidas, S/1998/780, 20 de agosto de 1998). Particularmente ilustrativas son las explicaciones proporcionadas por Turquía a propósito de ciertas operaciones emprendidas en territorio de Irak contra grupos terroristas que operaban desde bases establecidas en ese país. Aunque las incursiones turcas habían comenzado en 1991, el gobierno no había proporcionado justificación ante el 
adoptar medidas defensivas frente a los ataques realizados desde un país vecino «que no quiere o no puede» impedir que su territorio sea utilizado con tales fines $^{74}$. Las reacciones del resto de Estados ante estas pretensiones no reflejan que tales posiciones hayan obtenido un respaldo claro y mayoritario.

\subsection{Los atentados del 11 de septiembre de 2001 y la reacción de la comunidad internacional}

La reacción de la comunidad internacional ante los atentados del 11 de septiembre, manifestó un amplio reconocimiento del derecho a ejercer la legítima defensa individual y colectiva en respuesta a los atentados de $\mathrm{Al}$ Qaeda. Del reconocimiento del derecho de legítima defensa se desprende la aceptación de tales atentados, ejecutados por actores no estatales, como el «ataque armado» previsto en el artículo 51 de la Carta ${ }^{75}$.

El intenso debate doctrinal suscitado mostró la existencia de un sector proclive a la admisión de esta interpretación y de otro sector que cuestionaba esa calificación jurídica ${ }^{76}$. Uno de los elementos problemáticos, como se ha visto,

Consejo de Seguridad. En 1995, tras una serie de acciones de cierta envergadura, el gobierno de Turquia remitió una comunicación al Consejo. En ella se señalaba que Turquía no podía requerir al gobierno de Irak para que cumpliera su obligación de impedir que su territorio fuera utilizado para preparar ataques terroristas contra Turquía, porque el gobierno de Irak no ejercía un control efectivo en la zona norte del país. Turquía señaló que sus intervenciones, breves y de alcance limitado, no podían ser consideradas como una violación de la soberanía de Irak: «No cabe esperar que ningún país permanezca impasible mientras ve amenazada constantemente su propia integridad territorial por los flagrantes ataques transfronterizos de una organización terrorista establecida en un país vecino y que funciona desde allí, si ese país no es capaz de poner fin a tales ataques» (Consejo de Seguridad, S/1995/605, Carta de fecha 24 de julio dirigida al Presidente del Consejo de Seguridad por el encargado de negocios interino de la misión permanente de Turquía antes las Naciones Unidas, 24 de julio de 1995).

74 Vid. el escrito dirigido por Turquía al Consejo de Seguridad citado en la nota anterior.

75 Las posiciones adoptadas por la OTAN (Declaración del Consejo del Atlántico Norte, 12 septiembre de 2001, Press Release 2002/124, disponible <www.nato.int/docu/pr/2001/p01-124e.htm>) y por la Organización de Estados Americanos (vid., Organización de Estados Americanos, Resolución: Amenaza terrorista en las Américas, de 21 de septiembre de 2001 OEA/Ser.F/II.24, RC.24/RES.1/01) afirman expresamente que los atentados justificaban el ejercicio del derecho de legítima defensa colectiva. El Informe elaborado a petición del entonces Secretario General de la ONU, Kofi Annan por el Grupo de alto nivel sobre las amenazas, los desafíos y el cambio, titulado Un mundo más seguro: la responsabilidad que compartimos, califica la respuesta a los atentados del 11 de septiembre como «campaña militar de legítima defensa contra el régimen de los talibanes encabezada por los Estados Unidos» (cfr. Doc. A/59/565, de 2 de diciembre de 2004, p. 20, par. 14).

76 CAssese, A., «Terrorism is Also Disrupting Some Crucial Legal Categories of International Law», EfIL, vol. 12 (2001), 993-1001, p. 996. 
era la calificación de los actos terroristas como ataque armado rationae personae, por proceder de un actor no estatal y no resultar imputables a un Estado ${ }^{77}$.

Cabe interpretar que las resoluciones 1368 y 1373 del Consejo de Seguridad, al reconocer el «derecho inmanente de legítima defensa individual o colectiva de acuerdo con la Carta» aceptaban implícitamente el ejercicio de este derecho sobre el territorio de otro Estado, aunque el comportamiento del actor no estatal no resultara atribuible a dicho Estado ${ }^{78}$. No obstante, la innegable conexión que existía entre el régimen Talibán y el grupo Al Qaeda impone cierta cautela. Los atentados del 11 de septiembre no eran imputables al gobierno Talibán porque éste no había estado directamente implicado en su organización ni en su ejecución, tampoco poseía el grado de control necesario para que le resultaran atribuibles desde la perspectiva del derecho de la responsabilidad internacional del Estado ${ }^{79}$. No obstante, el gobierno Talibán otorgaba refugio a $\mathrm{Al}$ Qaeda en violación de sus obligaciones internacionales, tanto las derivadas de las resoluciones vinculantes del Consejo de Seguridad solicitando la entrega de Bin Laden ${ }^{80}$, como la obligación general que incumbe a todo Estado «de abstenerse de organizar, instigar, ayudar o participar... en actos de terrorismo en otro Estado o de consentir actividades dentro de

77 También se había cuestionado su calificación como ataque armado rationae materiae. Algunos autores abordaron este aspecto señalando que las excepcionales dimensiones de los atentados efectuados el 11 de septiembre (por los medios empleados, el número de víctimas y la destrucción ocasionada) así como el hecho de que uno de ellos tuviera un objetivo claramente militar, el Pentágono, justificaría su calificación como «ataque armado» en el sentido del artículo 51 de la Carta (en este sentido, EISEMANN, P.M., «Attaques du 11 septembre et exercice d'un droit naturel de légitime défense», BANNELIER, K. et al. (eds.), Le droit international face au terrorisme, pp. 239-248; BERMEJo GaRCía, R., «El Derecho Internacional frente al terrorismo: ¿Nuevas perspectivas tras los atentados del 11 de septiembre?)», Anuario de Derecho Internacional (2001), pp. 5-24).

78 Como se ha puntualizado, el reconocimiento del derecho de legítima defensa en las resoluciones 1368 (2001) y 1373 (2001) debe entenderse limitado a la situación concreta considerada por el Consejo, no como un reconocimiento generalizado del derecho de los Estados a responder a los atentados terroristas mediante el uso de la fuerza armada. En este sentido, RoBERTs, A., «Afghanistan and International Security», en Sснмітт, M. N. (ed.), The War in Afghanistan: A Legal Analysis, International Law Studies, vol. 85, Naval War College, 2009, p. 15. Al reconocer el derecho de legítima defensa, el Consejo de Seguridad despejaba cualquier duda que pudiera suscitarse respecto a su postura ante una eventual intervención militar de Estados Unidos (REISMAN, W. M., «International Legal Dynamics and the Design of Feasible Missions: The Case of Afghanistan» The War in Afghanistan: A Legal Analysis, International Law Studies, vol. 85, Naval War College, 2009, p. 63).

79 De hecho, los argumentos de Estados Unidos no plantean que los atentados del 11 de septiembre hubieran sido cometidos por orden o bajo control del gobierno afgano, o que le fueran imputables por otras razones.

80 Resolución 1267 (1999) de 15 de octubre y resolución 1333 (2000), de 19 de diciembre. 
su territorio encaminadas a la comisión de dichos actos... cuando impliquen recurrir a la amenaza o al uso de la fuerza $\rtimes^{81}$. El gobierno Talibán, por último, ignoró el ultimátum estadounidense que exigía el cierre de las bases de $\mathrm{Al}$ Qaeda y la entrega de Bin Laden y demás dirigentes de Al Qaeda ${ }^{82}$. Estados Unidos, al informar al Consejo de Seguridad del inicio de la operación militar en Afganistán en ejercicio del derecho de legítima defensa contra Al Qaeda, se refirió el apoyo del régimen talibán afgano ${ }^{83}$.

En definitiva, aunque la implicación del gobierno talibán no alcanzaba el umbral establecido por la CIJ en el asunto Nicaragua para que los atentados del 11 de septiembre pudieran calificarse como ataque armado, la comunidad internacional aceptó de manera prácticamente unánime el derecho a usar la fuerza en legítima defensa frente a los mismos.

Se planteaba la cuestión de si la respuesta internacional a los atentados del 11 de septiembre era reflejo de la evolución hacia una postura más flexible en cuanto al grado de implicación estatal necesario para calificar como ataque armado usos de la fuerza por actores no estatales ${ }^{84}$.

El grado de vinculación del gobierno afgano con la organización terrorista, a la que apoyaba además de proporcionarle refugio territorial, la excepcionalidad de los ataques y el reconocimiento por el Consejo de Seguridad del derecho de legítima defensa con carácter previo a su ejercicio, singularizan de tal modo el caso que limitan su valor como precedente. Se ha propuesto, en ese sentido, que sólo cabría ejercer el derecho de legítima defensa ante ataques de magnitud similar o si el Consejo de Seguridad lo reconoce en el caso concreto ${ }^{85}$. El análisis de la práctica posterior a 2001

81 Cfr. Resolución 2625 de la Asamblea General, de 24 de octubre de 1974, sobre la Declaración de los principios del Derecho Internacional referentes a las relaciones de amistad y a la cooperación entre los Estados de conformidad con la Carta de las Naciones Unidas.

82 The White House, Address to a foint Session of Congress and the American People, 20 de septiembre, 2001.

83 Consejo de Seguridad, Carta de fecha 7 de octubre de 2001 dirigida al Presidente del Consejo de Seguridad por el Representante Permanente de los Estados Unidos de América ante las Naciones Unidas, S/2001/946, 7 de octubre, 2001.

84 Moir, L., «Action Against Host States of Terrorist Groups», Weller, M. (ed.), The Oxford Handbook of the Use of Force in International Law, 2015, Oxford, OUP, pp. 720-36, p. 726.

85 Exigiendo un ataque de escala similar, CAssese, A., «Article 51», J. P. COT y A, Pellet (ed.), La Charte des Nations Unies, Paris, Economica, 2005, pp. 1329-61, y el previo reconocimiento del Consejo de Seguridad, GraY, C. «The Use of Force and the International Legal Order», en M. EvANS, International Law, $4^{\mathrm{a}}$ ed., OUP, 2014, citados por RuYs, T., «Armed Attack...», cit., p. 442 . 
muestra un mayor número de supuestos de Estados que responden frente a los ataques de actores no estatales Estado invocando el derecho a usar la fuerza en legítima defensa cuando el Estado vecino «no puede o no quiere» impedir el uso de su territorio por el grupo armado. El grado de conexión entre gobierno y actor no estatal existente en cada caso varia, desde la imposibilidad de evitar la presencia territorial del grupo, a la tolerancia pasiva o un mayor grado de apoyo. Y también varía la reacción de la comunidad internacional, sin que sea posible inferir un claro posicionamiento jurídico de los Estados.

La opinión consultiva de la CIJ en el asunto sobre las consecuencias jurídicas de la construcción de un muro en los Territorios palestinos ocupados, en 2004, supuso un revés para esta interpretación más flexible del derecho de legítima defensa. Un año más tarde, en el asunto relativo a las actividades militares sobre territorio del Congo, en el caso que enfrentaba a la República Democrática del Congo (RDC) con Uganda, la Corte parecía reafirmar la interpretación restrictiva del asunto Nicaragua.

En el primer asunto, el problema de si la noción de «ataque armado» a efectos del ejercicio de la legítima defensa incluye los ataques de actores no estatales ocupa un lugar central. Israel había invocado su derecho de legítima defensa frente a ataques terroristas cometidos por grupos no estatales palestinos basándose en las resoluciones 1368 (2001) y 1373 (2001) del Consejo de Seguridad ${ }^{86}$. El dictamen de la Corte Internacional de Justicia, tras citar el artículo 51 de la Carta, señaló que dicho artículo reconocía «la existencia de un derecho inmanente de legítima defensa en caso de ataque armado por un Estado contra otro Estado» ${ }^{87}$ para concluir a continuación que Israel no podía invocar las resoluciones 1368 y 1373 en su apoyo porque ejercía el control sobre los territorios de donde procedían los atentados terroristas, a diferencia de los atentados contemplados en las resoluciones citadas, que habían sido efectuados desde el exterior ${ }^{88}$. Pese al tenor literal del pronun-

86 I.C.7. Reports 2004, p. 194, par. 138.

87 I.C.7. Reports 2004, par. 139. Pese a la afirmación de la Corte, el artículo 51 no estipula expresamente que sólo se puede ejercer la legítima defensa frente a un ataque armado realizado por otro Estado. Varios jueces criticaron esta afirmación de la opinión consultiva, vid. I.C.7. Reports 2004, Opinión separada de la juez Higgins, p. 215, par. 33; Opinión Separada del Juez Kooijmans, pp. 229-30, par. 35; Opinión Separada del Juez Buergenthal, pp. 242-43, par. 6.

$88 \mathrm{El}$ pronunciamiento no resulta enteramente coherente. Inicialmente, el argumento que parece descartar la pertinencia del derecho de legítima defensa invocado por Israel es el hecho de que los ataques emanen de un actor no estatal, y la Corte se basa en el tenor literal del art. 51 de la 
ciamiento reproducido, la Corte parecía rechazar el argumento israelí de la legítima defensa no porque los ataques provinieran de un actor no estatal sino porque no procedían del exterior. Implícitamente, la Corte estaba otorgando relevancia a las resoluciones 1368 y 1373 para interpretar el alcance de la legítima defensa, aunque sin proporcionar ningún criterio orientativo adicional ${ }^{89}$.

En el asunto de las actividades armadas sobre territorio del Congo, Uganda pretendía justificar su ocupación de una superficie significativa de territorio congoleño ${ }^{90}$ invocando su derecho de legítima de defensa frente a una serie de ataques armados. $\mathrm{Al}$ analizar las circunstancias de hecho, la Corte subrayó que los «ataques armados» a los que específicamente se refería Uganda en ese argumento no provenían de las fuerzas armadas del Congo sino de un grupo rebelde enfrentado al gobierno ugandés (ADF), que no se daban los requisitos para que su conducta resultara atribuible a la RDC y que, por consiguiente, «no concurrían las circunstancias de hecho y de derecho necesarias para el ejercicio de un derecho de legítima defensa por Uganda contra la $\mathrm{RDC} \gg{ }^{91}$. Los dos párrafos dedicados a motivar el rechazo de esta pretensión ugandesa parecían descartar la posibilidad de calificar como «ataque armado» los usos de fuerza armada por actores no estatales, aunque en términos muy confusos. Aunque las circunstancias del caso y algunos puntos de las memorias de las partes ofrecían ocasión para analizar del problema, la Corte descartó sorprendentemente la relevancia del derecho de legítima defensa en el caso, declarando innecesario pronunciarse sobre varios aspectos del mismo suscitados por las partes ${ }^{92}$. A pesar de lo cual, del pronunciamiento se desprende implícitamente una respuesta negativa a la cuestión que la Corte pretendía

Carta, que no contiene una estipulación expresa en ese sentido. A renglón seguido, sin embargo, se señala que las resoluciones 1368 y 1373 invocadas por Israel en su apoyo, y que sí parecen admitir la legítima defensa frente a ataques de actores no estatales, no resultan aplicables al caso porque los ataques contra Israel no proceden del exterior.

89 En este mismo sentido, RuYs, «Armed attack...», cit., p. 474-5.

90 Armed Activities on the Territory of the Congo (Democratic Republic of the Congo v. Uganda), Fudgment, I.C.F. Reports 2005, p. 168. En gráfica síntesis, la Corte se refiere al control de «aeropuertos y poblaciones [de la RDC] situados a varios cientos de kilómetros de la frontera de Uganda» para señalar que, aunque se hubieran dado las condiciones de ejercicio del derecho de legítima defensa, difícilmente se podría considerar que las acciones de Uganda son proporcionadas a los ataques transfronterizos ante los que pretendidamente responden (p. 224, par. 147).

91 I.C.7. Reports 2005, p. 224, par. 147.

92 En este sentido, vid. RuYs, T., Armed Attack..., cit., pp. 480-5, y bibliografía citada. 
soslayar, reafirmando la postura restrictiva adoptada en el asunto de las actividades militares y paramilitares en Nicaragua ${ }^{93}$.

En esta situación, el enfrentamiento del Estado Islámico con el gobierno de Irak desde sus posiciones en territorio sirio e iraquí, y la respuesta armada de la coalición militar encabezada por Estados Unidos contra el EI plantea de nuevo las condiciones para que los Estados definan su posición respecto a los problemas analizados.

\section{Las posturas sobre el uso de la fuerza en legítima defensa contra objetivos del Estado Islámico en Siria}

En el presente caso, los actos del Estado Islámico no son atribuibles al Estado en que se refugia (Siria), de hecho la entidad terrorista combate al gobierno sirio. Nos encontramos ante un Estado al que no resulta atribuible la conducta del grupo, que tampoco le presta apoyo pero que carece de la capacidad para poner fin a sus acciones armadas.

2.1. Derecho de legítima defensa colectiva en apoyo de Irak, e individual de algunos miembros de la coalición internacional

Los títulos jurídicos aducidos por los Estados participantes en la coalición han experimentado una evolución al hilo de determinados acontecimientos.

a) La posición de Estados Unidos: derecho de legítima defensa individual (con matices) y colectiva

El 23 de septiembre de 2014 Estados Unidos informó al Consejo de Seguridad de las acciones militares emprendidas contra el Estado Islámico sobre territorio sirio, fundamentando su intervención en dos bases jurídicas. En primer lugar, el ejercicio de la legítima defensa colectiva en apoyo de Irak. El primer párrafo de la carta menciona los continuos ataques efectuados por el EIIL contra Irak a través de su frontera con Siria y la petición del gobierno iraquí

93 I.C.7. Reports 2005, par. 140, 145. La Corte había resaltado previamente que los objetivos de la operación militar emprendida en suelo congoleño, tal y como los enuncia el documento oficial el Alto Mando ugandés, tienen un carácter eminentemente preventivo («proteger los legítimos intereses de Uganda en materia de seguridad», «evitar que el vacío político en el Congo no afecte de modo adverso a Uganda» entre otros) y no hace referencia a que Uganda haya sido víctima de ataques armados previos por parte de la RDC. 
para que Estados Unidos dirigiera «los esfuerzos internacionales destinados a atacar los emplazamientos y bastiones militares del EIIL en Siria» ${ }^{94}$. En segundo lugar, la carta invoca, de manera vaga, el derecho de legítima defensa individual y colectiva ante la amenaza que el EIIL y otros grupos terroristas en Siria representan para «muchos otros países», incluidos los Estados Unidos y sus aliados.

$\mathrm{Al}$ no contar con el consentimiento de Siria para operar sobre su territorio, Estados Unidos procedió a una elaboración más detallada para justificar el ejercicio de la legítima defensa:

«los Estados deben ser capaces de defenderse, de conformidad con el derecho inmanente de legítima defensa, individual o colectiva, reflejado en el artículo 51 de la Carta de las Naciones Unidas, cuando, como ocurre en este caso, el Gobierno del Estado donde se encuentra la amenaza no quiere o no puede impedir que su territorio se utilice para realizar los ataques.» ${ }^{95}$

Aunque Estados Unidos había invocado el derecho de legítima individual y colectiva de Estados Unidos y otros países frente al EI, en el presente caso señala haber adoptado «medidas militares proporcionadas y necesarias» sólo con el objeto de eliminar la amenaza actual que el EIIL representa para Irak.

Situándose en otro plano, Estados Unidos informaba de que había «emprendido acciones militares en Siria contra elementos de Al-Qaeda conocidos como el grupo Khorasan para hacer frente a la amenaza terrorista que representan para los Estados Unidos y [sus] socios y aliados» ${ }^{96}$. Estas acciones separadas emprendidas por Estados Unidos a título individual, sin previo requerimiento del gobierno iraquí ni participación de la coalición, son justificadas alegando el ejercicio del derecho de legítima defensa individual (de Estados Unidos) y colectiva (de los aliados de Estados Unidos que sean objetivo de tales grupos terroristas). Ahora bien, para que las operaciones militares contra estos grupos queden efectivamente amparadas en esta legítima defensa individual, o colectiva pero desvinculada de Irak, Estados Unidos tiene que demostrar la existencia de una amenaza real e inminente de ataques terroristas por

94 Naciones Unidas, Consejo de Seguridad, Carta de fecha 23 de septiembre de 2014 dirigida al Secretario General por la Representante Permanente de los Estados Unidos de América ante las Naciones Unidas, S/2014/695, 23 de septiembre, 2014.

95 Ibid. La carta de Irak, sin embargo, había eludido mencionar expresamente a Siria optando en su lugar por una enigmática referencia a los «lugares donde se encuentra el EIIL».

96 Ibidem. 
parte de los mismos ${ }^{97}$. La única información que se da a este respecto es que son «elementos de Al Qaeda». Esta argumentación enlaza más bien con la reivindicación de un derecho de legítima defensa preventiva frente a amenazas latentes. Una concepción que traspasa los límites comúnmente aceptados del derecho de legítima defensa, que contempla la respuesta frente a un ataque consumado o inminente, pero no ataques preventivos contra una amenaza más remota ${ }^{98}$.

b) Francia: el paso de la legítima defensa colectiva a la legítima defensa individual

La declaración realizada por el Presidente Hollande tras los primeros ataques franceses contra posiciones del Estado Islámico en Irak, el 19 de septiembre de 2014, invocó la solicitud de ayuda formulada por Irak como justificación para poner en marcha una campaña de ataques aéreos con el fin de debilitar al grupo terrorista y de proporcionar apoyo a las autoridades iraquíes ${ }^{99}$. Aunque Francia restringió sus operaciones militares a objetivos del EI situados en Irak, tal limitación territorial no respondía a reservas jurídicas sobre la licitud de operar en Siria según se desprende de las declaraciones del Ministro Francés de Asuntos Exteriores» ${ }^{100}$.

Un año después las autoridades francesas extendieron sus ataques a las áreas del territorio sirio controladas por el Estado Islámico. En la notificación

97 Arimatsu, L. y Schmitt, M. N., «Attacking 'Islamic State'..., cit., p. 14.

98 Tanto el Informe del Grupo de alto nivel sobre las amenazas, los desafíos y el cambio, (Doc. A/59/565, de 2 de diciembre de 2004; par. 188), como el Informe del Secretario General titulado Un concepto más amplio de libertad: desarrollo y derecho bumanos para todos (Doc. A/59/2005, de 21 de marzo de 2005) afirman explícitamente que el artículo 51 de la Carta contempla la legítima defensa tanto frente a ataques ya consumados como frente a ataques inminentes (par. 124), pero no frente a amenazas latentes (par. 125). Esta es la posición que cuenta con un mayor apoyo doctrinal en la actualidad, vid. al respecto DeEKs, A., «Taming the Doctrine of Pre-Emption», Weller, M. (ed.), The Oxford Handbook of the Use of Force..., cit., pp. 661-677.

99 Présidence de la République, Déclaration du Président au sujet de l'Irak, 19 de septiembre de 2014 (disponible en el sitio oficial de la presidencia de la República francesa, <www.elysee.fr/declarations/article/declaration-du-president-au-sujet-de-l-irak>).

100 Tanto en Irak como en Siria, había declarado el Ministro, los ataques contra el Estado Islámico descansarían en el mismo fundamento jurídico «la posible legítima defensa, a título del artículo 51» (Ministerio francés de Asuntos Exteriores, Déclarations officielles de politique étrangère du 23 septembre 2014, Conférence de presse de M. Laurent Fabius, ministre des Affaires étrangères et du Développement international; Nueva York, 22 de septiembre de 2014, disponible en http://basedoc.diplomatie.gouv.fr/vues/Kiosque/FranceDiplomatie/kiosque. php? fichier=bafr2014-09-23.html\#top) 
dirigida al Consejo de Seguridad, Francia invocaba nuevamente las disposiciones del art. 51 de la Carta, pero sin específicar si estaba procediendo a título de la legítima defensa individual o colectiva ${ }^{101}$. La mención a la solicitud de asistencia de Irak permite interpretar que se amparaba sólo en la legítima defensa colectiva. En contrapartida, la observación de que los actos terroristas del Estado Islámico constituyen no sólo una amenaza para la paz y seguridad internacionales, según se recoge en varias resoluciones del Consejo de Seguridad, sino también una «amenaza directa y extraordinaria para la seguridad de Francia» podría suscitar dudas. Dudas que pueden ser descartadas a posteriori, pues las declaraciones de diferentes autoridades francesas tras los atentados del 13 de noviembre de 2015 en París, confirman que el discurso jurídico francés se había basado hasta ese momento sólo en la legítima defensa colectiva.

El Presidente Hollande, en una intervención ante el Parlamento tres días después de los atentados, caracterizó los actos terroristas como «actos de guerra», declaró que el país había sido víctima de una agresión y que, por consiguiente, Francia se encontraba en «estado de guerra» contra el Estado Islámico ${ }^{102}$. El Presidente francés activó igualmente, por primera vez desde su institución, la cláusula de legítima defensa colectiva establecida en el art. 42.7 del Tratado de la Unión Europea ${ }^{103}$. El Ministro de Defensa explicó ante el Parlamento la evolución jurídica de la situación: la legítima defensa colectiva, en la que se había apoyado inicialmente Francia para asistir a Irak se veía complementada en lo sucesivo por el derecho de legítima defensa individual. La

${ }^{101}$ Consejo de Seguridad, Cartas idénticas de fecha 8 de septiembre de 2015 dirigidas al Secretario General y al Presidente del Consejo de Seguridad por el Representante Permanente de Francia ante las Naciones Unidas, S/2015/745, 9 de septiembre de 2015. El 7 de septiembre el Presidente de la República había anunciado la decisión de ampliar el teatro de operaciones de las intervenciones francesas a Siria. El 27 de septiembre tuvieron lugar los primeros ataques aéreos contra bases del Estado Islámico en territorio sirio. Tras los atentados de París, de 13 de noviembre, el Presidente francés anunció la intensificación de las operaciones aéreas contra el EI y el despliegue de un grupo aeronaval en el Mediterráneo oriental (información disponible en la página oficial del Ministerio de Defensa francés, <www.defense.gouv.fr/operations/irak-syrie/chronologie/ chammal-retour-sur-les-dates-cles-de-l-intervention-militaire-francaise-au-levant>.

102 Francia, Sénat, Message de François Hollande, Président de la République au Parlement, 16 de noviembre de 2015, disponible en <www.senat.fr/evenement/archives/D46/hollande.html>. En el mismo discurso informaba de que había efectuado un ataque aéreo contra un puesto de mando del EIIL en la ciudad siria de Raqqa y de que se incrementarían las operaciones militares contra el Estado Islámico en Siria.

${ }^{103}$ La solicitud de asistencia recibió el apoyo unánime de los Estados miembros en la reunión del Consejo de Asuntos Exteriores de la Unión Europea, celebrada en Bruselas, los días 16 y 17 noviembre de 2015. 
resolución 2249 (2015) del Consejo de Seguridad, añadía, proporcionaba una legitimidad adicional a la actuación francesa que quedaba enmarcada dentro del Derecho Internacional y del respeto a la Carta de las Naciones Unidas ${ }^{104}$.

c) Reino Unido: la solicitud de asistencia y la legítima defensa colectiva e individual

El documento que expone la posición jurídica del gobierno británico respecto a las acciones militares contra el Estado Islámico en Irak, invoca como fundamento jurídico el consentimiento del Estado territorial, admitido en el Derecho internacional como excepción al principio de prohibición del uso de la fuerza en las relaciones internacionales ${ }^{105}$. Durante meses Irak había solicitado la asistencia de la comunidad internacional para luchar contra el EIIL y para proteger su territorio y a su población; en agosto de 2014 había dirigido una petición específica en este sentido a Reino Unido y el 20 de septiembre había remitido una carta al Consejo de Seguridad que recogía su expresa petición de asistencia militar prestada bajo la forma de ataques aéreos efectuados por una coalición internacional bajo dirección de Estados Unidos. Un conjunto de circunstancias que, a juicio del gobierno británico, proporcionaban «una base jurídica clara e inequívoca para el despliegue de personal y material militar por Reino Unido con el fin de emprender acciones militares apara atacar emplazamientos y bastiones militares del EIIL en Irak» ${ }^{106}$. El Parlamento aprobó la propuesta del gobierno y autorizó bombardeos aéreos contra el Estado Islámico en territorio iraquí, en el entendimiento de que no se extenderían a Siria sin someter nuevamente la cuestión al Parlamento ${ }^{107}$. Reino Unido, en consecuencia, ciñó sus ataques aéreos a objetivos situados en Irak durante más de un año ${ }^{108}$.

\footnotetext{
${ }^{104}$ En este mismo sentido, vid. la intervención del representante francés ante el Consejo de Seguridad tras la adopción de la resolución 2249 (S/PV.7565, 20 de noviembre 2015, 2).

105 Reino Unido, Prime Minister's Office, Policy Paper, Summary of the Government Legal Possition on Military Action in Iraq against ISIL, 25 de septiembre de 2014.

106 Ibidem.

${ }^{107}$ Reino Unido, House of Commons, Debate, 26 de septiembre de 2014, Col. 1255.

${ }^{108}$ La única acción militar realizada antes de recibir la aprobación parlamentaria para operar en Siria reviste un perfil diferente. Reino Unido efectuó un ataque letal selectivo mediante una aeronave tripulada por control remoto, invocando su derecho de legítima defensa para actuar contra un nacional británico, miembro del EIIL, acusado de haber planificado y de seguir planificando atentados contra el Reino Unido y otros países. En el ataque, efectuado el 21 de agosto de 2015, además del operativo que constituía su objetivo, murieron otros dos miembros del EIIL, uno de los cuales tenía también nacionalidad británica. Vid. la explicación del Primer Ministro ante el Parlamento, en Reino Unido, House of Commons Debates, 7 de septiembre de 2015, col. 25.
} 
La posición jurídica expuesta en el documento, sin embargo, no refleja plenamente la postura Reino Unido. La referencia exclusiva a la petición y el consentimiento de Irak evoca la figura de la intervención por invitación. Sin embargo, al informar al Consejo de Seguridad «de conformidad con el artículo 51 de la Carta de las Naciones Unidas», de las medidas adoptadas en respuesta a los requerimientos de ayuda del gobierno iraquí, Reino Unido justificó sus acciones en «la legítima defensa colectiva del Iraq, en el marco de los esfuerzos internacionales encabezados por los Estados Unidos» ${ }^{109}$. Desde el principio su participación en la campaña militar contra el Estado Islámico descansó en la legítima defensa colectiva de Irak. La petición de asistencia por el gobierno iraquí, que considerada aisladamente remite a la figura de la intervención militar por invitación, es mencionada por Reino Unido en cuanto requisito para el ejercicio de la legítima defensa colectiva en apoyo de Irak, Estado víctima del ataque.

Interpretación que se ve reforzada con ocasión de la extensión de los ataques a Siria. A lo largo del año 2015 el Gobierno barajó en varias ocasiones la posibilidad de acudir de nuevo ante la Cámara con ese objetivo ${ }^{110}$. Finalmente, la propuesta de ampliar los ataques aéreos contra el Estado Islámico a territorio sirio fue llevada al Parlamento y aprobada el 2 de diciembre de $2015^{111}$.

Con carácter previo, el Comité de Asuntos Exteriores de la Cámara de los Comunes, había presentado un informe analizando, entre otros aspectos, las posibles bases jurídicas de las operaciones militares contra el EI. Nuevamente, la base jurídica de las operaciones en Irak es enfocada desde la perspectiva de la invitación del gobierno territorial, un enfoque no viable en el caso de Siria por lo que era necesario buscar fundamentos jurídicos alternativos ${ }^{112}$, reducidos a

109 Consejo de Seguridad, S/2014/851, 26 de noviembre de 2014.

${ }^{110}$ House of Commons, Foreign Affairs Committee, The extension of offensive British military operations to Syria, Second Report of Session 2015-16, HC 457, 3 de noviembre de 2015, p. 5-6. Aunque el gobierno británico no necesita formalmente obtener la autorización del Parlamento para emprender acciones militares, se ha instaurado esta costumbre que se intenta respetar siempre que sea posible (ibid.).

111 Probablemente la influencia de la derrota sufrida por el Ejecutivo en 2013, cuando el Parlamento votó en contra de su propuesta de realizar ataques aéreos contra el régimen de Assad en respuesta a la utilización de armas químicas, llevaría a retrasar la presentación de una nueva iniciativa (House of Commons, Debate, 2 de diciembre, 2015, Col. 321 y ss).

112 Aunque el régimen de Assad había mostrado cierta tolerancia ante los ataques de la coalición sobre objetivos del Estado Islámico en Siria, a diferencia de Irak no había formulado una invitación a la coalición internacional para actuar en su territorio. Por otro lado, desde noviembre de 2012, el gobierno británico reconocía a la Coalición nacional de las fuerzas revolucionarias 
la existencia de una resolución del Consejo de Seguridad autorizando el uso de la fuerza ${ }^{113} \mathrm{o}$ al ejercicio del derecho de legítima defensa. En el momento de presentación del informe el Consejo de Seguridad no había adoptado aún ninguna resolución sobre este aspecto. Por lo que se refiere al derecho de legítima defensa, aunque otros Estados integrantes de la coalición internacional ya habían emprendido ataques aéreos en Siria invocando el ejercicio del derecho de legítima defensa de Irak en su apoyo, el Comité juzgó que no existía una formulación satisfactoria de la legítima defensa que demostrara su aplicabilidad al enfrentamiento con el EI en Siria ${ }^{114}$. Por esta razón, el informe concluía que antes de solicitar la aprobación del Parlamento para extender las operaciones aéreas a Siria el gobierno debería explicar, entre otros aspectos, cómo afrontaría los problemas jurídicos derivados de la ausencia de una resolución del Consejo de Seguridad ${ }^{115}$.

Desde la publicación del informe hasta la remisión de la respuesta por parte del Primer Ministro, diferentes acontecimientos habían contribuido a una transformación significativa de la situación. Entre ellos, la escalada en la intensidad de los ataques del EIIL fuera de Siria e Irak, incluidos los cometidos el 13 de noviembre en París, y la adopción unánime por el Consejo de Seguridad de la Resolución 2249, de 20 de noviembre de 2015.

La respuesta del Primer Ministro al Comité, por lo tanto, abordó la fundamentación jurídica de la eventual extensión de la campaña aérea a Siria en un contexto nuevo. Cabe reseñar, por lo que se refiere al valor de la resolución 2249 del Consejo de Seguridad, que el Primer Ministro no la invocó como base jurídica para extender los ataques contra el Estado Islámico en Siria. Tras citar los párrafos que contienen la unánime determinación de que el EIIL «constituye una amenaza mundial sin precedentes para la paz y la seguridad internacionales» y la exhortación dirigida a los Estados para que «adopten

y de la oposición sirias y no al Presidente Assad, como único representante legítimo del pueblo sirio. En este sentido, una invitación procedente del gobierno de Assad no resolvería el problema. Esta era también la posición de Estados Unidos y Francia, si bien Rusia y China seguían reconociendo el régimen de Assad como único gobierno legítimo (House of Commons, Foreign Affairs Committee, HC 457, cit., ap. 18).

113 A juicio de los autores del informe este era el escenario más deseable, tanto desde la perspectiva jurídica como política, porque la adopción de una resolución por el Consejo de Seguridad «requería la negociación entre todas las partes y un compromiso para alcanzar una respuesta consensuada». (House of Commons, Foreign Affairs Committee, HC 457, cit., ap. 19).

114 Ibid., ap. 20.

115 Ibid., ap. 35.a.iii). 
todas las medidas necesarias... para prevenir y reprimir los actos terroristas cometidos específicamente por el EIIL ${ }^{116}$ no derivó conclusión alguna. Se limitó a proponer el derecho de legítima defensa individual y colectiva como «base jurídica clara» para la acción militar contra el EI en Siria ${ }^{117}$.

La argumentación del Primer Ministro subraya la continuidad entre las acciones contra el Estado Islámico en Siria y en Irak: el fundamento jurídico de las acciones militares en Siria era el mismo que servía de base para las efectuadas en Irak, es decir, el derecho de legítima defensa colectiva de Irak. La única razón por la que el Reino Unido no había participado directamente en acciones militares sobre territorio sirio era el compromiso del gobierno de no hacerlo sin antes obtener la autorización del Parlamento. De hecho, desde octubre de 2014 había empezado a contribuir con los esfuerzos de la coalición en Siria mediante misiones de vigilancia aérea y de inteligencia. Esta ampliación de la contribución británica respondía a la constatación de la estrecha relación entre la presencia y actividades del EIIL en Siria y sus continuos ataques en Irak, y también de que el régimen de Assad no quería o no podía emprender las acciones necesarias para poner fin a los ataques del Estado Islámico en Irak ${ }^{118}$. Aunque no emprendiera acciones militares contra el EIIL en Siria, había dejado constancia ante el Consejo de Seguridad de su pleno apoyo a las acciones de la coalición «que tienen por objeto poner fin a los continuos ataques contra el Iraq... mediante ataques contra los emplazamientos y bastiones militares del EIIL en Siria, como medidas necesarias y proporcionales ${ }^{119}$.

$\mathrm{Al}$ mismo tiempo, la respuesta del Primer Ministro incorporaba una base jurídica adicional: el derecho de legítima defensa individual del Reino Unido, y eventualmente colectiva en favor de otros aliados, contra el Estado Islámico. La argumentación utilizada procede gradualmente. Por un lado, deja constancia de que el EI representa una amenaza fuera de Irak y de Siria por su capacidad para planificar ataques contra Reino Unido y sus aliados en otras partes del mundo. A continuación, hace referencia a la Resolución 2249 mediante la que el Consejo de Seguridad se hace cargo de la situación y, tras condenar

\footnotetext{
116 Reino Unido, Memorandum to the Foreign Affairs Select Committee, Prime Minister's Response to the Foreign Affairs Select Committee's Second Report of Session 2015-16: The Extension of Offensive British Military Operations to Syria, noviembre de 2015, p. 15, <www.parliament.uk/documents/ commons-committees/foreign-affairs/PM-Response-to-FAC-Report-Extension-of-Offensive-British-Military-Operations-to-Syria.pdf>.

117 Ibidem.

118 Ibid., p. 16.

119 S/2014/851, 26 de noviembre de 2014, cit.
} 
los ataques del Estado Islámico en ciudades de diferentes países, exhorta a los Estados a prevenir tales ataques. Finalmente, concluye que la campaña del EI contra Reino Unido y sus aliados había alcanzado el umbral de un «ataque armado» legitimando por consiguiente el ejercicio de la fuerza en legítima defensa para prevenir nuevos ataques ${ }^{120}$.

\section{La posición de Siria: consentimiento del Estado territorial y ejercicio del derecho de legítima defensa contra un actor no estatal}

Los Estados que cuestionan la licitud de los ataques de la coalición contra las bases del Estado Islámico en Siria forman un grupo reducido. En él se encuentran la propia Siria y sus aliados tradicionales, Irán y Rusia. El Ministro ruso de Asuntos Exteriores, en respuesta al inicio de la campaña de la coalición contra el EI en Siria y a la declaración del Presidente de Estados Unidos, señaló:

«tales acciones se pueden realizar única y exclusivamente dentro del marco del derecho internacional. Esto supone no una 'notificación' unilateral de los ataques, sino la presencia de un consentimiento claramente explícito del gobierno de Siria o la adopción de la correspondiente resolución del Consejo de Seguridad de la ONU.»121

Similar fue la reacción del Presidente de Irán, para quien las acciones eran ilícitas por no contar con la autorización de las Naciones Unidas ni con el permiso de Siria, a diferencia de las intervenciones realizadas en Irak a invitación del gobierno iraquí1 ${ }^{122}$.

$\mathrm{El}$ régimen de $\mathrm{Al}$ Assad ha subrayado reiteradamente que los ataques de la coalición internacional sobre las bases del EI en su territorio son ilícitos porque no cuentan con su consentimiento ${ }^{123}$. Antes del inicio de la campaña

\footnotetext{
120 Prime Minister's Response to the Foreign Affairs..., cit., p. 17.

${ }_{121}$ Ministerio de Asuntos Exteriores, Declaración del Ministerio de Asuntos Exteriores de Rusia en relación con los ataques en el territorio de Siria, 23 de septiembre de 2014 (disponible en la página oficial del Ministerio de Asuntos Exteriores de la Federación de Rusia, <www.mid.ru/es/kommentarii_predstavitelya/-/asset_publisher/MCZ7HQuMdqBY/content/id/669677>).

122 NBC News, 23 de septiembre de 2014, Iran Leader Criticizes U.S. Strikes on ISIS in Syria, Calls Them Illegal, <www.nbcnews.com/storyline/isis-terror/iran-leader-criticizes-u-s-strikesisis-syria-calls-them-n209536>.

123 «yrria's President Speaks. A Conversation With Bashar al-Assad», Foreign Affairs, 16 de febrero de 2015 (disponible en <www.foreignaffairs.com> interviews/2015-01-25/syrias-presidentspeaks)..
} 
militar sobre el territorio de Siria, un miembro del gobierno sirio ya había señalado ante los medios de comunicación que cualquier intervención extranjera en Siria constituiría un acto de agresión a menos que hubiera sido aprobada por Damasco, subrayando la disposición del gobierno sirio para cooperar con cualquier Estado con el fin de luchar contra el Estado Islámico ${ }^{124}$. La sesión celebrada por el Consejo de Seguridad el 19 de septiembre de 2014 fue ocasión para que el representante sirio reafirmara

«que toda iniciativa internacional de lucha contra el terrorismo debe basarse en el pleno respeto de la Carta y las disposiciones y los principios del derecho internacional, en particular aquellos que respaldan la soberanía de los Estados. En consecuencia, es preciso coordinar a un alto nivel con el Gobierno de Siria todo esfuerzo digno de crédito que se realice para combatir el terrorismo.» ${ }^{125}$

Desde entonces, el gobierno sirio ha rechazado constantemente la licitud de las acciones militares de la coalición en Siria, manifestando su oposición a cualquier afirmación contenida en informes de la Organización que comporte una legitimación de las mismas ${ }^{126}$.

Inicialmente Siria no denunció los ataques de la coalición contra el Estado Islámico ante el Consejo de Seguridad. Dejaba constancia de su oposición, como se ha señalado, pero sin llevar la situación al Consejo. Las primeras denuncias

124 «Syria warns against foreign intervention», Aljazeera, 11 de septiembre 2014. Pocos días después del inicio de los ataques de la coalición, a principios de octubre de 2014, en sus observaciones escritas a un Informe del Secretario General, reiteraba su apoyo a «todos los esfuerzos internacionales para combatir el terrorismo» siempre que respetaran el derecho internacional y la soberanía nacional (Asamblea General-Consejo de Seguridad, A/69/411-S/2014/705, 1 de octubre de 2014, par. 21). En otra reunión del Consejo de Seguridad, de 19 de noviembre de 2014, se refería a la alianza establecida por algunos Estados «fuera del marco de las Naciones Unidas y sin un mandato del Consejo de Seguridad para llevar a cabo ataques aéreos contra el ISIL en Siria y el Iraq». (Consejo de Seguridad, 7316ª sesión, S/PV.7316, 19 de noviembre de 2014, p. 36).

125 Consejo de Seguridad, 7271ª sesión, 19 de septiembre de 2014, S/PV.7271, 19 de septiembre de 2014, p. 46.

${ }^{126}$ En este sentido, vid. las observaciones formuladas a propósito del Informe del Secretario General sobre la aplicación de las resoluciones del Consejo de Seguridad por todas las partes en el conflicto sirio ( $S / 2015 / 962)$, en las que «rechaza los intentos de los autores del informe de legitimar las operaciones militares que lleva a cabo en Siria la denominada coalición dirigida por los Estados Unidos de América» que violan de forma flagrante el derecho internacional. Se opone igualmente a la pretensión de equiparar las operaciones de la coalición con las realizadas por la Fuerza Aérea Rusa, que constituyen una respuesta a la solicitud oficial formulada por el Gobierno sirio y comunicado a las Naciones Unidas (S/2015/1006, de 30 de diciembre de 2015, par. 7). 
contra acciones de la coalición fueron presentadas al Consejo transcurrido más de un año desde el inicio de la campaña militar y pueden agruparse en dos grandes categorías. La primera engloba las reacciones de Siria en rechazo de los fundamentos jurídicos invocados por los Estados de la coalición como base de sus acciones. Con leves variaciones de forma, tres son los elementos centrales de la posición formulada por Siria. En primer lugar, la incongruencia de la invocación del consentimiento de un tercer Estado, Irak, como base para intervenir sobre territorio sirio $^{127}$. Estrechamente vinculado se encuentra el argumento referido a la incompatibilidad de la campaña militar con la Carta y con las resoluciones pertinentes del Consejo se Seguridad, «en particular las resoluciones 2170 (2014), 2178 (2014) y 2199 (2015), en las que se pone de relieve que los Estados deben respetar la unidad, la soberanía y la integridad territorial de la República Árabe Siria» ${ }^{128}$ y de la más específica resolución $2249(2015)^{129}$. En segundo lugar, la «distorsionada» interpretación del derecho de legítima defensa en que se escudan las acciones de la coalición ${ }^{130}$. Por último, el hecho de que el ejército sirio ha luchado de modo continuado con los grupos terroristas presentes en su territorio (Estado Islámico, el Frente Al-Nusra y otras organizaciones asociadas con Al-Qaida) y de que en esta lucha el gobierno está abierto a la colaboración con cualquier otro agente ${ }^{131}$. Aseveraciones aparentemente dirigidas a neutralizar el eventual recurso al argumento de que Siria «no puede o no quiere» poner fin a las acciones del Estado Islámico desde su territorio.

En la segunda categoría se encontrarían las denuncias formales dirigidas por Siria al Consejo de Seguridad relativas a acciones concretas de la coalición contra la infraestructura económica, industrial y de servicios ${ }^{132}$ o contra uni-

127 Consejo de Seguridad, S/2015/719, 21 de septiembre de 2015. Siria respondía a las cartas con las que el Reino Unido (S/2015/688, de 8 de septiembre de 2015) y Australia (S/2015/693, de 9 de septiembre de 2015) habían informado al Consejo de Seguridad de los ataques armados que iban a emprender y del fundamento jurídico en que se apoyaban. En el mismo sentido, vid. Asamblea General-Consejo de Seguridad, A/70/385-S/2015/727, 22 de septiembre de 2015 y A/70/673-S/2015/1048, 4 de enero de 2016, par. 4.

$128 \mathrm{Vid}$. S/2015/719, 21 de septiembre de 2015.

129 A/70/673-S/2015/1048, 4 de enero de 2016, par. 6. El gobierno sirio, ha reivindicado constantemente que para «luchar contra el terrorismo en el territorio sirio es necesario que exista una estrecha cooperación y coordinación con el Gobierno sirio», ibid., par. 4

${ }^{130} \mathrm{~S} / 2015 / 719$, 21 de septiembre de 2015; A/70/385-S/2015/727, 22 de septiembre de 2015 y A/70/673-S/2015/1048, 4 de enero de 2016, par. 4.

$131 \mathrm{~S} / 2015 / 719,21$ de septiembre de 2015; A/70/385-S/2015/727, 22 de septiembre de 2015 y A/70/673-S/2015/1048, 4 de enero de 2016, par. 2.

132 En este sentido, vid. S/2015/851, 16 de noviembre de 2015; A/70/671-S/2015/1043, 30 de diciembre de 2015, A/70/654-S/2015/1014, 7 de enero de 2016; S/2016/31, 12 enero 2016; 
dades militares de Siria ${ }^{133}$. Cabe destacar que el gobierno sirio ha informado al Consejo de Seguridad, y condenado, los ataques terroristas cometidos en su territorio ${ }^{134}$, también las incursiones terrestres y otros tipos de ataques efectuados por las fuerzas armadas turcas ${ }^{135}$. Sin embargo, Siria nunca ha denunciado ante el Consejo los bombardeos de la coalición que no afectan a infraestructuras o instalaciones de servicios básicos. Esto no significa que se refrende su legitimidad. Como se ha señalado Siria ha afirmado de modo constante que las acciones armadas de la coalición sobre su territorio carecen de todo fundamento jurídico en Derecho Internacional, pero concilia esta postura de principio con la ausencia de protesta ante ataques efectivamente dirigidos contra el Estado Islámico.

\section{La Resolución 2249 (2015) del Consejo de Seguridad: UNANIMIDAD SOBRE UN CONTENIDO MÍNIMO Y AMBIGÜEDAD EN CUANTO A SU SIGNIFICADO}

El Consejo de Seguridad se pronunció sobre la situación en agosto de 2014 mediante la resolución 2170 (2014) $)^{136}$, en la que se refiere el efecto desestabilizador de la presencia del Estado Islámico y del Frente Al-Nusra (FAN) sobre Siria e Irak y los demás países de la región, observando finalmente que representaban una amenaza para la paz y seguridad internacionales. Situándose en el marco del capítulo VII el Consejo pasó a condenar las acciones terroristas del Estado Islámico, las violaciones de derechos humanos y del derecho internacional humanitario cometidas por el grupo y adoptó una serie de medidas, vinculantes unas, otras en términos exhortación, para luchar contra el grupo en diferentes ámbitos: financiación, propaganda, reclutamiento

\footnotetext{
S/2016/174, 2 de marzo de 2016. La mayoría de las comunicaciones de Siria al Consejo incluyen una cláusula en virtud de la cual Siria se reserva el derecho de exigir las pertinentes reparaciones de los países responsables. Para una estimación de los daños causados en instalaciones de petróleo y gas por los bombardeos de la coalición desde el inicio de la campaña hasta el 31 de marzo de 2016, vid., S/2016/343, 20 de abril de 2016.

133 Consejo de Seguridad, S/2015/933, 8 de diciembre de 2015.

134 Vid., a título de ejemplo, Consejo de Seguridad, S/2015/132, 25 de febrero de 2015; S/2016/415, 11 de mayo de 2016, a propósito los «atentados terroristas indiscriminados que algunos grupos terroristas armados han perpetrado en barrios residenciales pacíficos de la ciudad de Alepo en estas dos últimas semanas».

135 Consejo de Seguridad, S/2015/998, de 21 de diciembre de 2015.

${ }^{136}$ Consejo de Seguridad, S/RES/2170 (2014), 15 de agosto de 2014.
} 
y circulación de miembros del grupo, corte de cualquier forma de suministro de recursos económicos y militares. La resolución 2178, adoptada por unanimidad, aprobó diferentes medidas de lucha contra el terrorismo en virtud del capítulo VII, subrayando «la particular y urgente necesidad de aplicar la presente resolución a los combatientes terroristas extranjeros asociados con el EIIL, el Frente Al-Nusra y otras células, entidades afiliadas o grupos escindidos o derivados de Al-Qaida». Estas primeras resoluciones del Consejo se sitúan dentro de la línea de la lucha contra el terrorismo internacional inaugurada por la resolución 1373 (2001) de 28 de septiembre ${ }^{137}$.

\section{Efectos de las resoluciones del Consejo de Seguridad en el derecho de legítima defensa}

La resolución 2249 (2015) del Consejo de Seguridad, adoptada por unanimidad a partir de una propuesta presentada por Francia tras los atentados de París, adopta un enfoque diferente ${ }^{138}$, más próximo al de la resolución 1267 (2001), aunque también con alguna diferencia significativa.

Una característica que las separa es que la resolución 2249 (2015) no menciona explícitamente el derecho de legítima defensa. Tal omisión no significa que el Consejo de Seguridad repudie en el presente caso la invocación del derecho de legítima defensa colectiva, o individual y colectiva, como base jurídica de las operaciones armadas llevadas a cabo por diferentes Estados en Siria ${ }^{139}$. El Consejo de Seguridad está facultado, si lo considera necesario, para rechazar, limitar y poner fin al ejercicio del derecho de legítima defensa, conforme al artículo 51 in fine. Pero la práctica del Consejo pone de manifiesto que su decisión en ese sentido debe ser clara ${ }^{140}$, circunstancia que no concurre

${ }^{137}$ En la Resolución 1373 (2201), el Consejo de Seguridad establecía un conjunto de obligaciones para los Estados miembros con el objeto de suprimir la financiación del terrorismo y de mejorar la cooperación internacional en la lucha antiterrorista, situándolas en el marco del capítulo VII.

138 Aunque también conecta con las resoluciones centradas en los diferentes mecanismos de lucha contra el terrorismo internacional, al manifestar la necesidad de actualizar la Lista de sanciones del Comité 1267 para tener en cuenta la amenaza que representa el Estado Islámico (punto 7 del dispositivo).

139 En este mismo sentido, MarTin, J.-C., «Les frappes de la France contre l'EIIL en Syrie» Questions of International Law, vol. 24 (2016), pp. 3-14, p. 10.

140 La práctica muestra que el Consejo de Seguridad ha rechazado reivindicaciones de legítima defensa condenando usos de la fuerza, o que ha puesto fin a su ejercicio exigiendo cese de las hostilidades, pero también que algunas medidas coercitivas adoptadas por el Consejo de Seguridad pueden coexistir con el ejercicio de la legítima defensa. En este sentido, SCHACHTER, O., 
en el presente caso. De hecho, aunque no contenga una referencia expresa a la legítima defensa, algunas afirmaciones de la resolución 2249 parecen avalar la concurrencia de los requisitos que justifican su ejercicio.

En primer lugar, la parte dispositiva de la resolución comienza con una condena enérgica de los ataques terroristas cometidos por el Estado Islámico ${ }^{141}$, y refiriéndose al grupo terrorista el Consejo de Seguridad «observa que tiene la capacidad y la intención de realizar nuevos ataques» ${ }^{142}$. El ejercicio del derecho de legítima defensa colectiva en favor de Irak sobre territorio sirio no necesita demostrar que el Estado Islámico tiene capacidad e intención de efectuar nuevos ataques. El grupo ocupó, y retiene, por la fuerza parte del territorio iraquí y este sólo dato justifica el ejercicio del derecho por parte de Irak y de sus aliados. En un escenario donde el enfrentamiento entre el Estado Islámico y las fuerzas armadas de los Estados territoriales reviste las características de un conflicto armado en curso, los ataques aéreos de la coalición pueden desarrollarse de manera continuada, sin necesidad de identificar un ataque previo del Estado islámico que los justifique. Dentro de la vaguedad con que está formulado el párrafo, la referencia específica a «horrendos ataques terroristas» que han sido cometidos por el Estado Islámico fuera del teatro de operaciones de Siria e Irak, la observación de que el EI ha demostrado la capacidad e intención de cometer nuevos atentados de similares características, apuntan más bien al reconocimiento eventual de un derecho de legítima defensa individual del Estados víctima de tales atentados. Resulta difícil admitir que las dimensiones de los atentados del 13 noviembre en Francia, justifiquen el uso de la fuerza contra el Estado Islámico en Siria, o en Irak, invocando el derecho de legítima defensa individual, aunque se añada la consideración de que el Estado Islámico ha demostrado su capacidad

\footnotetext{
«United Nations Law in the Gulf Conflict», American fournal of International Law (1991), p. 456; Bermejo García, R., El marco jurídico..., cit., pp. 312-322; CORTEN, O., Le droit contre la guerre..., 707-718; DinsteIn, Y., War, Agression..., cit., pp. 236-9.

141 Una condena generalizada acompañada de la mención expresa a los cometidos en la ciudad tunecina de Susa el 26 de junio de 2015, en Ankara el 10 de octubre, en el Sinaí el 31 de octubre, en Beirut el 12 de noviembre y en París el 13 de noviembre (par. 1).

142 En el primer párrafo del dispositivo el Consejo de Seguridad. «1. Condena inequívocamente en los términos más enérgicos los horrendos ataques terroristas perpetrados por el EIIL, también conocido como Daesh, que tuvieron lugar el 26 de junio de 2015 en Susa (Túnez), el 10 de octubre de 2015 en Ankara, el 31 de octubre de 2015 sobre el Sinaí, el 12 de noviembre de 2015 en Beirut y el 13 de noviembre de 2015 en París, así como todos los demás ataques perpetrados por el EIIL, también conocido como Daesh, incluidos los casos de toma de rehenes y asesinatos, observa que tiene la capacidad y la intención de realizar nuevos ataques y considera que todos esos actos de terrorismo constituyen una amenaza para la paz y la seguridad».
} 
e intención de seguir cometiendo ataques, e incluso tomando en consideración los atentados sufridos por Francia con posterioridad a la adopción de la resolución. Sin profundizar en este aspecto, la gravedad del ataque y la posibilidad de acumular una serie de ataques a efectos de esa valoración, no se puede dejar de señalar lo problemática que resulta la aserción francesa, al igual que las del Reino Unido y de Estados Unidos, del derecho de legítima defensa individual. Se explica, en este sentido, la búsqueda de una fuente de legitimidad adicional, como una resolución del Consejo de Seguridad que declare que se reúnen las condiciones para el ejercicio de legítima defensa individual, siguiendo en esto una de las líneas interpretación del la resolución 1368 en relación con los atentados del 11 de septiembre ${ }^{143}$.

La declaración del representante de Francia ante el Consejo de Seguridad tras la aprobación de la resolución confirmaría que esa era la intención de Francia al someter el proyecto de resolución:

«Los atentados del 13 de noviembre constituyeron un acto de agresión armada contra Francia. Nuestras medidas militares, de las que hemos informado al Consejo de Seguridad desde el principio, que estaban justificadas como medidas de legítima defensa colectiva, pueden en adelante fundamentarse igualmente en la legítima defensa individual, de conformidad con el artículo 51 de la Carta de las Naciones Unidas. Sobre la base de esta resolución histórica del Consejo de Seguridad, Francia proseguirá y aumentará sus esfuerzos para movilizar a toda la comunidad internacional a fin de vencer a nuestro enemigo común.» ${ }^{144}$

En segundo lugar, el Consejo de Seguridad no sólo no pone freno a las operaciones estatales contra el Estado Islámico sino que las alienta. En efecto, en el párrafo 5 de la resolución 2249, el Consejo:

«Exhorta a los Estados Miembros que tengan capacidad para hacerlo a que adopten todas las medidas necesarias, de conformidad con el derecho internacional, en particular la Carta de las Naciones Unidas (...) sobre el territorio que se encuentra bajo el control del EIIL, también conocido como Daesh, en Siria y el Iraq, redoblen y coordinen sus esfuerzos para prevenir y reprimir los actos terroristas cometidos específicamente por el EIIL (...), así como el Frente Al-Nusra, y todas las demás personas, grupos, empresas y

\footnotetext{
${ }^{143}$ Esta invocación de la legítima defensa individual refleja un acercamiento con la postura de Estados Unidos en este ámbito jurídico.

${ }^{144}$ Consejo de Seguridad, $7565^{\text {a }}$ sesión, 20 de noviembre de 2015, S/PV.7565, p. 2.
} 
entidades asociados con Al-Qaida y otros grupos terroristas designados por el Consejo de Seguridad de las Naciones Unidas (...) y erradiquen el cobijo que han establecido en partes importantes del Iraq y Siria.» ${ }^{145}$

La exhortación a adoptar «todas las medidas necesarias», siguiendo la línea de interpretación antes propuesta, se puede entender como un reconocimiento genérico de la licitud de las operaciones militares que se emprendan contra el EI, siempre que procedan «de conformidad con el derecho internacional y la Carta de la ONU». El llamamiento queda circunscrito adicionalmente en cuanto al sujeto contra el que los Estados puede dirigir sus medidas, el Estado Islámico, y al territorio donde se pueden realizar tales medidas, el territorio de Siria e Irak que se encuentra bajo control del Estado Islámico. La resolución parece reservar un trato diferente al Frente Al-Nusra, y demás grupos y entidades asociados con Al-Qaeda, frente a los cuales anima a coordinar los esfuerzos estatales para prevenir y reprimir sus acciones, erradicando los refugios territoriales con que cuentan en Siria e Irak. Cuál sea el alcance práctico de la distinción queda por determinar.

En definitiva, la resolución 2249, parece estar anticipando a los Estados su valoración de que concurren los requisitos para que ejerzan su derecho de legítima defensa en respuesta a ataques terroristas del Estados Islámico mediante operaciones dirigidas contra la organización terrorista en las áreas que ocupa de Siria e Irak. No se concede con ello carta blanca para cualquier tipo de actuación. El Consejo, en efecto, apostilla que los Estados deben proceder «de conformidad con el derecho internacional, en particular la Carta de las Naciones Unidas». Si se acepta esta interpretación, el Consejo de Seguridad estaría reaccionando de una forma que probablemente no tenga precedentes, ante «la amenaza sin precedentes para la paz y la seguridad internacionales», que a juicio del Consejo representa el Estado Islámico.

\section{La resolución 2249 (2015) como eventual base jurídica para la acción contra Estado Islámico y otros grupos terroristas}

Podría considerarse que la cualificada gravedad de la situación hubiera recomendado la adopción de medidas coercitivas en virtud del artículo 42. Resulta evidente, sin embargo, que las posturas contrapuestas de los miembros

145 Resolución 2249 (2015), par. 5. 
permanentes del Consejo respecto al régimen sirio hubiera abocado al fracaso una iniciativa en este sentido. La resolución no adopta medidas coercitivas que incluyan la autorización del uso de la fuerza y por lo tanto no proporciona en sí misma una nueva base jurídica, un título autónomo para usar la fuerza contra el Estado Islámico ${ }^{146}$.

Es modo de proceder habitual en el Consejo determinar que una situación constituye una amenaza para la paz y seguridad internacionales (art. 39 de la Carta), situarse explícitamente en el marco del capítulo VII y «autorizar»a los Estados, y organismos regionales en su caso, a «utilizar todos los medios necesarios» para restablecer el mantenimiento de la paz y seguridad internacionales. En el presente caso, el Consejo de Seguridad efectúa la determinación prevista en el artículo 39, en los siguientes términos:

«Determinando que, por su ideología extremista violenta, sus actos terroristas, sus ataques constantes, flagrantes, sistemáticos y generalizados dirigidos contra la población civil... el Estado Islámico en el Iraq y el Levante (EIIL, también conocido como Daesh) constituye una amenaza mundial sin precedentes para la paz y la seguridad internacionales,

Recordando que el Frente Al-Nusra y demás personas, grupos, empresas y entidades asociados con Al-Qaida también constituyen una amenaza para la paz y la seguridad internacionales.» ${ }^{147}$

La resolución 2249 utiliza igualmente la expresión «adoptar todos los medios necesarios», y en este sentido está contemplando el uso de la fuerza por parte de los Estados. En el preámbulo, el Consejo de Seguridad se había mostrado «decidido a combatir por todos los medios esta amenaza sin precedentes para la paz y la seguridad internacionales». En definitiva, utiliza términos de diferentes disposiciones del capítulo VII y algunas de las expresiones más significativas a las que recurre el Consejo de Seguridad cuando autoriza el uso de la fuerza, pereo la resolución carece de elementos esenciales. Los pronunciamientos relevantes del dispositivo no han sido enmarcados expresamente dentro del capítulo VII. Tampoco se utiliza los términos «decide»y

146 En este sentido, Martin, J-C., «Les frappes de la France...», cit., p. 13; AKande, D. y MilaNOVIC, M., «The Constructive Ambiguity of the Security Council's ISIS Resolution», EFIL: Talk!, 21 de noviembre, 2015, <www.ejiltalk.org/the-constructive-ambiguity-of-the-securitycouncils-isis-resolution/>...

147 Consejo de Seguridad, S /RES/2249 (2015), Resolución 2249, de 20 de noviembre, párrafos quinto y sexto del preámbulo. 
«autorizar», a los que recurre el Consejo cuando adopta medidas coercitivas en virtud del artículo 42, en su lugar se formula una «exhortación» a actuar ${ }^{148}$.

La ambigüedad del texto permite dar cabida a interpretaciones contrapuestas, algo indispensable para que la resolución pudiera ser adoptada por unanimidad. En este sentido, la resolución es invocada por los Estados de la coalición en apoyo de la licitud de sus ataques aéreos en territorio sirio ${ }^{149}$. En ella se apoyan también Siria y Rusia con el fin contrario, el de impugnar la licitud de los ataques aéreos de la coalición realizados sobre Siria sin el consentimiento del gobierno. Hay que tener presente que el texto propuesto por Francia tuvo que incorporar las «importantes enmiendas» ${ }^{150}$ presentadas por Rusia antes de ser aprobado, entre ellas la referencia expresa al respeto de la Carta de la ONU. La cláusula, que podría ser entendida como un mero recordatorio, para Rusia estaba cargada de significado. Conforme a la declaración del representante ruso en el Consejo de Seguridad, «la resolución de Francia es un llamamiento político más que una petición de cambiar los principios jurídicos en los se basa la lucha contra el terrorismo» ${ }^{151}$.

Las reiteradas protestas formuladas por Siria ante la pretensión de invocar la resolución 2249 como fundamento jurídico de los ataques realizados por los Estados de la coalición, resume esta interpretación:

«En la resolución 2249 (2015) del Consejo de Seguridad se destaca el respeto por la soberanía, la integridad territorial y la independencia política de todos los Estados de conformidad con la Carta. No se aprobó en virtud del capítulo VII de la Carta y no faculta a los Estados Miembros a emplear la fuerza militar ni les solicita que la empleen.»152

${ }^{148}$ En esta misma línea se pronuncia HilPOLD, P., «The fight against terrorism and SC Resolution 2249 (2015): towards a more Hobbesian or a more Kantian International Society?», Indian fournal of International Law, vol. 55, n. 4 (2015), pp. 535-555, p. 542.

149 Entre otras, vid. las referencias a la resolución 2249(2015) en comunicados dirigidos al Consejo de Seguridad por Bélgica (S/2016/523, de 9 de junio de 2016, Bélgica invoca como título de la legítima defensa colectiva en relación con Irak y de los Estados que hayan sufrido ataques del EI), Dinamarca (S/2016/34, 13 de enero de 2016) y Reino Unido (S/2015/928, de 3 de diciembre, que invoca su derecho de legítima defensa individual o colectiva).

${ }^{150}$ Según la calificación del propio representante de Rusia, con la que se deja claro la relevancia acordada a su inclusión en el texto de la resolución (Consejo de Seguridad, 7565 sesión, 20 de noviembre de 2015, S/PV.7565, p. 5.)

151 Consejo de Seguridad, $7565^{\text {a }}$ sesión, 20 de noviembre de 2015, S/PV.7565, p. 5.

152 Cartas idénticas de fecha 29 de diciembre de 2015 dirigidas al Secretario General y a la Presidenta del Consejo de Seguridad por el Representante Permanente de la República Árabe Siria ante las Naciones Unidas, A/70/673-S/2015/1048, 4 de enero de 2016, par. 6. 
Llegados a este punto cabe interrogarse qué finalidad persigue la adopción de la resolución 2249. De manera incuestionable, la resolución reconoce la amenaza excepcional, «sin precedentes», que el Estado Islámico supone para la paz y seguridad internacionales, tanto para los países donde tiene sus bases, Siria e Irak, como para otros países por su capacidad e intención de seguir efectuando ataques terroristas. Es un aspecto en el coinciden las declaraciones de los miembros del Consejo de Seguridad tras la adopción de la resolución. Todos los Estados perciben singularmente la amenaza que el terrorismo representa o puede representar para los mismos, y la voluntad de expresar la solidaridad con Francia tras los atentados de noviembre, aunque la resolución también condena otros atentados del Estado Islámico, facilitó la rápida aprobación del texto propuesto. También es incuestionable que la resolución hace un llamamiento generalizado a los Estados para combatir al Estado Islámico, utilizando todos los medios a su alcance conforme al orden jurídico internacional. Queda por determinar el valor de tal llamamiento.

Este es el significado no controvertido de la resolución, en el que concurren todos los miembros del Consejo. En los demás aspectos, la ambigüedad con que está redactada la resolución permite, como se ha expuesto, interpretaciones opuestas.

\section{Conclusiones}

Al hilo de las reflexiones sobre el alcance jurídico de la resolución 2249 del Consejo se irán formulando las conclusiones extraídas a lo largo del trabajo.

La resolución 2249, no adopta medidas coercitivas en virtud del capítulo VII de la Carta y, por lo tanto, no aporta una base jurídica autónoma para el uso de la fuerza contra el Estado Islámico y demás grupos terroristas en Siria e Irak. Las únicas bases serían el consentimiento de Irak, en relación con los objetivos presentes en territorio iraquí y con las matizaciones apuntadas en su momento, y el ejercicio de la legítima defensa colectiva para los objetivos ubicados en territorio sirio. Irak, y Siria en su caso, pueden estar legitimados para el ejercicio del derecho de legítima defensa individual frente al Estado Islámico más cuestionable es la admisibilidad de este título para los demás países de la coalición.

La resolución 2249 ha sido invocada por la mayoría de los Estados de la coalición al informar al Consejo de Seguridad de las acciones emprendidas en 
el ejercicio de la legítima defensa contra el Estado Islámico en Irak. Su aprobación representaba para algunos países un respaldo legitimador del ejercicio del derecho de legítima defensa individual de los Estados víctimas de ataques del EI desvinculada de la solicitud de asistencia de Irak. Esta indudable ampliación de la base jurídica original para el uso de la fuerza viene acompañada de dos límites. Uno de carácter subjetivo (sólo contra el Estado Islámico) y otro de carácter territorial (sólo en las zonas de Siria e Irak bajo el control del Estado Islámico). Puede que esta singularización persiga una finalidad garantista, al crear un contexto tan definido limita la posibilidad de generalizar los efectos de la resolución.

Hemos anticipado cómo, a nuestro juicio, es una interpretación ajustada a la finalidad declarada de Francia y al lenguaje de la declaración... con la salvedad de que la declaración no menciona explícitamente el derecho de legítima defensa. $\mathrm{Al}$ mismo tiempo, aceptar esta interpretación no equivale a reconocer en general la licitud del uso de la fuerza por los Estados de la coalición, sea a título de legítima defensa individual o colectiva. La remisión de la resolución a las normas de derecho internacional y a las disposiciones de la Carta sirve para contener las interpretaciones potencialmente innovadoras, como había señalado Rusia.

La remisión a un marco jurídico cuyo contenido es objeto de interpretaciones profundamente distintas en la práctica internacional y en la doctrina, no en sí misma particularmente clarificadora. Algunos de los elementos de la resolución, sin embargo, apuntan aspectos en los que la práctica internacional parece revestir una mayor uniformidad.

La situación descrita en el trabajo, los ataques efectuados por el Estado Islámico en Irak y en Siria y la respuesta armada de la coalición internacional, también de Rusia a solicitud de Siria, parecen reflejar una superación de la interpretación de la Corte Internacional de Justicia sobre los requisitos de ejercicio de la legítima defensa contra actores no estatales. La práctica internacional refleja que los Estados invocan la legítima defensa para reaccionar frente a los ataques de grupos armados no imputables a un Estado y en los que tampoco hay una participación sustancial de un Estado. En algunos casos, el Estado territorial ofrece cierto apoyo al grupo armado o lo tolera. En otros, el grupo opera en áreas fuera del control del Estado o que, como en el presente caso, ha pasado a controlar por la fuerza ante la oposición ineficaz del Estado territorial. La actitud del Estado en cuyo territorio se refugia la entidad terrorista y desde donde efectúa ataques es uno de los elementos más controvertidos en Siria. Estados Unidos y los países de la coalición alegan que 
Siria «no puede o no quiere» poner fin a los ataques y presencia del Estado en su territorio. Siria, por el contrario, afirma que pone medios eficaces y se declara dispuesta a cooperar, por lo que rechaza que el uso de la fuerza contra el Estado Islámico en su territorio sea lícito sin contar con su consentimiento. Siendo irreconciliables en cuanto a la apreciación de los hechos, la postura de Siria manifiesta implícitamente su acuerdo sobre la sustancia de la norma propuesta por los miembros de la coalición: la admisibilidad del derecho de legítima defensa contra un actor no estatal cuando el Estado en cuyo territorio se encuentra no puede o no quiere poner fin a su presencia o a sus actividades. 